\title{
Article
}

\section{Degradable and injectable hydrogel for drug delivery in soft tissues}

Vincent Pertici, Caroline Pin-barre, Claudio Rivera, Christophe

Pellegrino, Jeröme Laurin, Didier Gigmes, and Thomas Trimaille

Biomacromolecules, Just Accepted Manuscript • Publication Date (Web): 30 Oct 2018

Downloaded from http://pubs.acs.org on October 30, 2018

\section{Just Accepted}

"Just Accepted" manuscripts have been peer-reviewed and accepted for publication. They are posted online prior to technical editing, formatting for publication and author proofing. The American Chemical Society provides "Just Accepted" as a service to the research community to expedite the dissemination of scientific material as soon as possible after acceptance. "Just Accepted" manuscripts appear in full in PDF format accompanied by an HTML abstract. "Just Accepted" manuscripts have been fully peer reviewed, but should not be considered the official version of record. They are citable by the Digital Object Identifier (DOI®). "Just Accepted" is an optional service offered to authors. Therefore, the "Just Accepted" Web site may not include all articles that will be published in the journal. After a manuscript is technically edited and formatted, it will be removed from the "Just Accepted" Web site and published as an ASAP article. Note that technical editing may introduce minor changes to the manuscript text and/or graphics which could affect content, and all legal disclaimers and ethical guidelines that apply to the journal pertain. ACS cannot be held responsible for errors or consequences arising from the use of information contained in these "Just Accepted" manuscripts. 


\title{
Degradable and injectable hydrogel for drug delivery in soft tissues
}

\author{
Vincent Pertici ${ }^{1}$, Caroline Pin-Barre ${ }^{2}$, Claudio Rivera ${ }^{3}$, Christophe Pellegrino ${ }^{3}$, Jérôme Laurin ${ }^{2}$, \\ Didier Gigmes ${ }^{1 *}$, Thomas Trimaille ${ }^{*}$ \\ ${ }^{1}$ Aix Marseille Univ., CNRS, ICR, Marseille, France. \\ ${ }^{2}$ Aix Marseille Univ., CNRS, ISM, Marseille, France. \\ ${ }^{3}$ Aix Marseille Univ., INSERM, INMED, Marseille, France.
}

*Corresponding authors.didier.gigmes@univ-amu.fr; thomas.trimaille@univ-amu.fr.

Aix-Marseille Université (AMU) et Centre National de la Recherche Scientifique (CNRS), UMR 7273 «Institut de Chimie Radicalaire» (ICR), Equipe «Chimie Radicalaire Organique et Polymères de Spécialité » (CROPS), Case 542 - Avenue Escadrille Normandie-Niemen, F-13397 Marseille Cedex 20, France. Tel./fax: +33 491288083.

\begin{abstract}
Injectable hydrogels are promising platforms for tissue engineering and local drug delivery as they allow minimal invasiveness. We have here developed an injectable and biodegradable hydrogel based on an amphiphilic PNIPAAm-b-PLA-b-PEG-b-PLA-b-PNIPAAm pentablock synthesized by ring-opening polymerization/nitroxide-mediated polymerization (ROP/NMP) combination. The hydrogel formation at around $30^{\circ} \mathrm{C}$ was demonstrated to be mediated by intermicellar bridging through the PEG central block. Such result was particularly highlighted by the inability of PEG-PLA-PNIPAAm triblock analog of same composition to gelify. The hydrogels degraded through hydrolysis of PLA esters, until complete mass loss due to the diffusion of the recovered PEG and PNIPAAM/micelle based-residues in the solution. Interestingly, hydrophobic molecules such as riluzole (neurotrophic drug) or cyanine 5.5 (imaging probe) could be easily loaded in the hydrogels' micelle cores by mixing them with the copolymer solution at room temperature. Drug release was correlated to polymer mass loss. The hydrogels were shown to be cytocompatible (neuronal cells, in vitro) and injectable through small-gauge needle (in vivo in rats). Thus, this hydrogel platform displays highly attractive features for use in brain/soft tissue engineering as well as in drug delivery.
\end{abstract}




\section{Introduction}

Injectable hydrogels are highly attractive biomaterials in drug delivery and tissue engineering ${ }^{1}$. Although the use of hydrogels for brain disorders is still restricted to preclinical investigations, it is already considered as a very encouraging opportunity for the treatment of neurodegenerative diseases and cerebrovascular disorders in forthcoming years. Indeed, they allow for minimally invasive implantation and show unique mechanical properties in the range of living soft tissues, which is particularly required for brain and spinal cord ${ }^{2,3}$. They are also known to increase cell transplantation survival and stabilize short half-life drugs. Furthermore, polymer-based hydrogels could locally deliver pharmacological treatments in the host tissue limiting the risk of systemic side effects.

Many works have been dedicated to the design of injectable systems, either based on in situ crosslinking of synthetic/natural polymer precursors ${ }^{4-9}$ or on thermoresponsive (co)polymers ${ }^{10-}$ 13. The first approach is potentially efficient, but traces of toxic reagents/catalysts and/or use of UV irradiation source are serious concerns, which can alter entrapped drugs or cells. In addition, in situ gelation process upon crosslinking can be hard to control. In this regard, thermoresponsive polymers or copolymers able to self-gelify at body temperature, including Pluronics, ${ }^{14}$ poly(ethylene glycol) (PEG)-polyester based triblock copolymers, ${ }^{15,16}$ or polyacrylamides ${ }^{17}$ appear to be more benign and appropriate. Among them, poly( $\mathrm{N}$-isopropylacrylamide) (PNIPAAm) remains widely investigated due to its nearly ideal lower critical solution temperature (LCST) around $32{ }^{\circ} \mathrm{C}$ allowing it to collapse in water at physiological temperature ${ }^{18}$. However, PNIPAAm suffers some undesired features such as its pronounced hydrophobic character above LCST which induces hydrogel syneresis (i.e. water expulsion, gel shrinkage) ${ }^{19}$, leading to unsuitable mechanical properties as well as uncontrolled release of entrapped drugs/biomolecules. In addition, PNIPAAm is non-degradable, which poses the problem of longterm bioaccumulation at the implantation site of this acrylamide-based polymer whose biocompatibility and thus clinical development remain questionable, although it is non-cytotoxic in many biomedical applications ${ }^{20}$.

Different strategies have been developed to address these issues by incorporating hydrophilic poly(ethylene glycol) (PEG) segments to improve water uptake and limit syneresis ${ }^{21}$. Many authors have either proceeded through copolymerization of NIPAAm with few amounts of PEG 
dimethacrylate as crosslinker (chemical crosslinking) ${ }^{22}$, or by using PNIPAAm-b-PEG-bPNIPAAm-based triblock and/or star-block copolymer nanostructuration (physical crosslinking) ${ }^{23,24}$. However, these hydrogels consisting of high molecular weight polymer remain non-degradable and therefore hardly removable through renal clearance. As proposed by Abandansari et al., triblock architectures could be improved by introducing poly(caprolactone) (PCL) blocks between the central PEG block and the external PNIPAAm blocks so as to synthesize a degradable pentablock ${ }^{25}$. Nevertheless, PCL degrades very slowly, its content was low in the designed copolymer and no degradation analyses were reported. In other studies, PNIPAAm has been copolymerized with hydroxyethyl methacrylate (HEMA) and poly(lactide) (PLA) methacrylate macromer to improve hydrophilicity and degradability, respectively ${ }^{26}$. Despite an improved mass loss of the copolymer hydrogel over time, its properties were not really appropriate regarding injectability and water uptake (i.e. LCST around $15{ }^{\circ} \mathrm{C}$, pronounced gel shrinkage over time). Other comonomers were introduced in the PNIPAAm backbone such as acrylic acid-and dimethyl-gamma-butyrolactone (DBA) for hydrophilicity and poly(trimethylene carbonate)- or PCL-acrylate for degradability ${ }^{27,28}$. In these works, improvements were achieved by means of swelling, but the weight loss over time remained inferior to $20 \%$. Interesting studies took profit of the DBA as comonomer, since its hydrolysis over time leads to hydrophilic moieties along PNIPAAm backbone, which results in an increase of LCST up to $40^{\circ} \mathrm{C} 29,30$, allowing solubility of the copolymer and nearly total mass loss in vitro. However, the renal clearance of the molecular weights used (min. $30 \mathrm{kDa}$ ) remains questionable. More recently, PEG citrate acrylate was copolymerized with NIPAAm leading to copolymer hydrogels with improved swelling, but low mass loss ${ }^{31}$.

Another important concern in hydrogel engineering is the poor loading ability of hydrophobic drugs inherent to their hydrophilic character, as highlighted in many studies ${ }^{32,33}$. Thus, there is a crucial need to address this issue as many active drugs, either already marketed or in current clinical development, are hydrophobic. Consequently, there is still a high need for PNIPAAm-based injectable hydrogels presenting degradability, swelling, reduced PNIPAAm content, and loadability of a wide range of molecules for biofunctionalization.

Here we report on a symmetric pentablock copolymer platform based on PLA, PEG and PNIPAAm. Such amphiphilic structure allows gel formation through intermicellar crosslinking upon heating and degrades into low molar mass polymer chains once its intermediate PLA blocks 
are hydrolyzed. Moreover, it can be used as a delivery device for hydrophobic drugs by taking profit of the micelle core. In vitro cytocompatibility as well as in vivo injectability features in a brain tissue engineering context are also presented.

\section{Experimental section}

\subsection{Materials}

Monohydroxy PEG 4000 g.mol ${ }^{-1}$ and dihydroxy PEG 4000 g.mol ${ }^{-1}$ were purchased from TCI and Aldrich, respectively. D,L-Lactide was purchased from Corbion Purac, packaged under vacuum, and then stored under argon. Tin(II) 2-ethylhexanoate $\left(\mathrm{Sn}(\mathrm{Oct})_{2}\right)$, acryloyl chloride, NIsopropylacrylamide (NIPAAm), anhydrous toluene and 1,4-dioxane were purchased from Aldrich. Cyanine 5.5-carboxyl (Cy5.5), a near-infrared fluorescent probe, was purchased from FluoProbes. Riluzole, from Acros organics, is a neuroprotective agent that was incorporated in the hydrogel. The alkoxyamine MAMA-SG1 (commercialized by Arkema under the trade name of BlocBuilder MA) was kindly provided by Arkema (France). Triethylamine (TEA) was purchased from Acros Organics. Tetrahydrofuran (THF) was purchased from VWR. 1,4-dioxane was distilled prior to use and other solvents were used as received.

\subsection{Copolymer synthesis and characterization}

Pentablock copolymers were synthesized in 4 steps, namely 1) the ring-opening polymerization (ROP) of the D,L-lactide from the different commercial dihydroxy PEG (i.e. $\mathrm{PEG}_{45}$ and $\mathrm{PEG}_{91}$ ), 2) the acrylation of the terminal hydroxyl functions of the previously synthesized triblock copolymers, 3) the intermolecular radical 1,2-addition (IRA) of the alkoxyamine MAMA-SG1 onto the terminal vinyl functions and 4) the nitroxide-mediated polymerization (NMP) of the NIPAAm from the different macro-initiators (Scheme 1). 

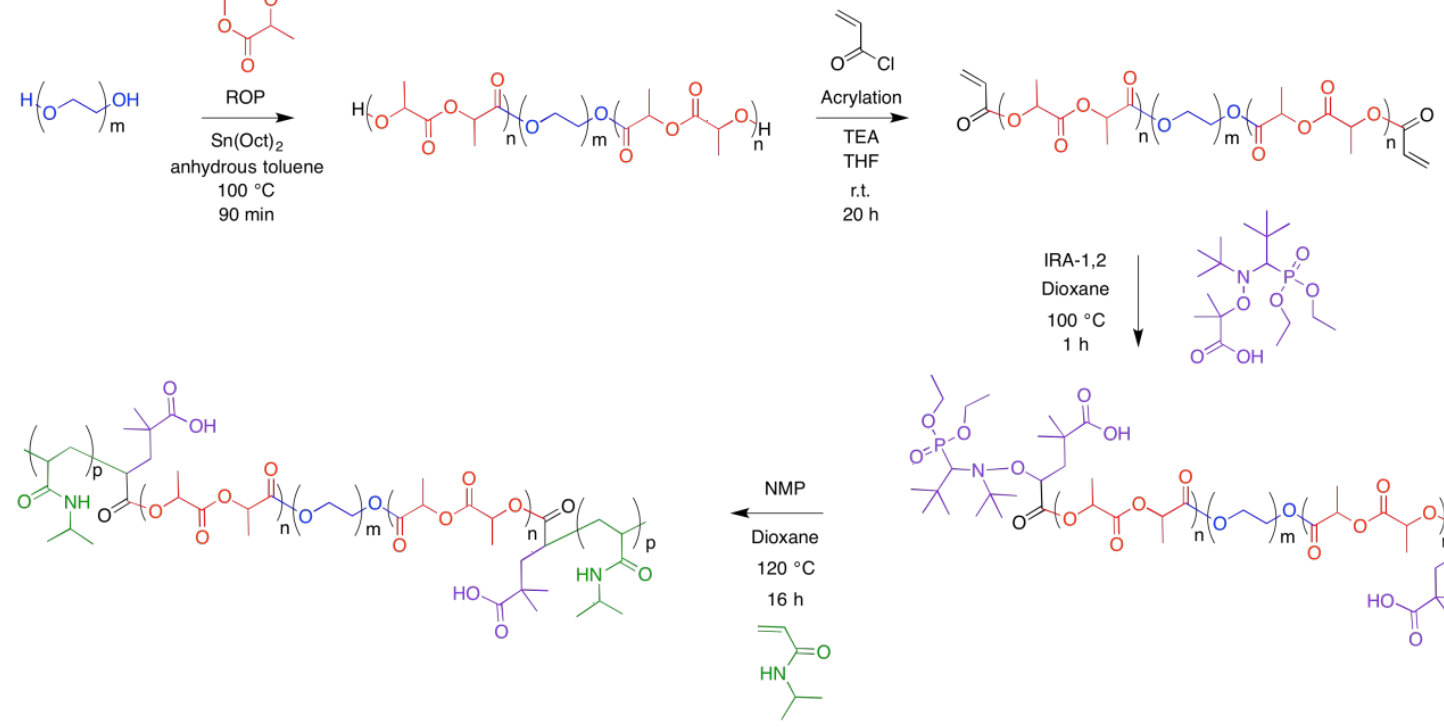
$20 \mathrm{~h}$
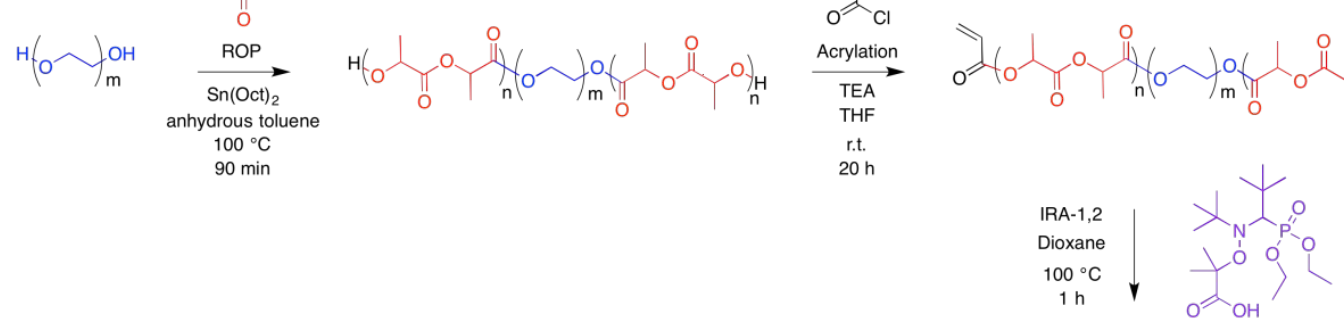

$\mathrm{h}$

Scheme 1. Pentablock copolymer synthesis pathway.

Numerous conditions were tested to evaluate the effect of each block length on the final pentablock copolymer. Additionally, a triblock copolymer analog of the most promising pentablock copolymer tested in this study (PNIPAAm $60-b-P_{14}-b-P_{14}-b-G_{91}-A_{14}-b-$ PNIPAAm 60 ) was synthesized through the same pathway by using a monohydroxy PEG $_{90}$. The different block copolymers are summarized in the table 1. As an example, the synthesis pathway of the above-mentioned pentablock is described below.

ROP of lactide from dihydroxy PEG. ROP of D,L-lactide was initiated by a $4000 \mathrm{~g} \cdot \mathrm{mol}^{-1}$ $\alpha, \omega$-dihydroxy $\mathrm{PEG}$ and catalyzed by $\mathrm{Sn}(\mathrm{Oct})_{2}$ (1 eq. per hydroxyl terminal function) in anhydrous toluene at $100{ }^{\circ} \mathrm{C}$. Typically, D,L-lactide $(10.00 \mathrm{~g}, 69.38 \mathrm{mmol})$ and PEG $(9.83 \mathrm{~g}$, $2.48 \mathrm{mmol}$, targeted $\left.\mathrm{Mn} \sim 8,000 \mathrm{~g} \cdot \mathrm{mol}^{-1}\right)$ were placed in a single neck Schlenk while $\mathrm{Sn}(\mathrm{Oct})_{2}$ $(1.00 \mathrm{~g}, 2.48 \mathrm{mmol})$ was placed in a sealed vial. Both containers were submitted to vacuum/argon cycles. Dry toluene $\left(35 \mathrm{~mL},[\mathrm{D}, \mathrm{L}-\right.$ lactide $\left.]=2 \mathrm{~mol} \cdot \mathrm{L}^{-1}\right)$ was then added through the septum under an argon atmosphere in the Schlenk, which was placed in an oil bath preheated at $100{ }^{\circ} \mathrm{C}$. Once homogenous and at the set temperature, $\mathrm{Sn}(\mathrm{Oct})_{2}$ was added to the mixture. The mixture was stirred for $2 \mathrm{~h}$ and then cooled down in a water bath. The polymer was precipitated in diethyl ether and dried at $30{ }^{\circ} \mathrm{C}$ under vacuum.

Diacrylated end-capped triblock copolymer. $\alpha, \omega$-Dihydroxy $\mathrm{PLA}_{14}-\mathrm{b}-\mathrm{PEG}_{90}-\mathrm{b}-\mathrm{PLA}_{14}(16 \mathrm{~g}$, $2.07 \mathrm{mmol}$ ) was allowed to react with acryloyl chloride $(3.38 \mathrm{~mL}, 41.47 \mathrm{mmol})$ (10 eq. per 
hydroxyl terminal function) in presence of TEA $(5.78 \mathrm{~mL}, 41.47 \mathrm{mmol})$ in THF $(240 \mathrm{~mL})$ at room temperature. After $20 \mathrm{~h}$ of reaction, the polymer was precipitated in cold diethyl ether and ethanol $(9: 1, v / v)$ and dried under vacuum.

Synthesis of the triblock copolymer macro-alkoxyamine. A solution of diacrylated endcapped PLA $14-\mathrm{b}-\mathrm{PEG}_{91}$-b-PLA 14 (2 g, $\left.0.26 \mathrm{mmol}\right)$ and MAMA-SG1 (1.95 g, $\left.5.11 \mathrm{mmol}\right)$ (10 eq. per hydroxyl terminal function) in dioxane $(6 \mathrm{~mL})$ was introduced in a sealed vial, deoxygenated by argon bubbling during $20 \mathrm{~min}$ and heated at $100^{\circ} \mathrm{C}$ for $1 \mathrm{~h}$ under stirring. The polymer was then precipitated in cold diethyl ether.

NMP of NIPAAm from the block copolymer macro-alkoxyamine. A solution of SG1 endcapped PLA 14 -b-PEG 90 -b-PLA 14 ( $1 \mathrm{~g}, 0.12 \mathrm{mmol})$ and NIPAAm (1.58 g, $13.98 \mathrm{mmol})$ (60 eq. per hydroxyl terminal function) in dioxane $(8 \mathrm{~mL})$ was introduced in a sealed vial, deoxygenated by argon bubbling during $20 \mathrm{~min}$ and heated at $120^{\circ} \mathrm{C}$ overnight under stirring. After polymerization, the mixture was cooled down and precipitated in cold diethyl ether.

\subsection{Analytical techniques}

${ }^{1} \mathrm{H}$ and ${ }^{31} \mathrm{P}$ nuclear magnetic resonance (NMR) spectra were recorded on a Bruker Advance $400 \mathrm{MHz}$ spectrometer to confirm polymerizations, end-chain functionalizations and degradation. The deuterated solvents used were deuterated chloroform $\left(\mathrm{CDCl}_{3}\right)$ and deuterated dimethyl sulfoxide $\left(\right.$ DMSO- $\left.\mathrm{d}_{6}\right)$.

Size exclusion chromatography (SEC) experiments, highlighting change in polymer length after polymerization reaction or degradation, were performed on a Varian PL-GPC 120 apparatus, which was composed of a PL-AS-MT autosampler, an Agilent 1100 series pump, a degasser, an injection valve, a column oven and a refractive index (RI) detector. The following columns were used: one pre-column and two PL Resipore columns (300 mm $\AA \sim 7.8 \mathrm{~mm}$ ). The injection loop, the columns and the RI detector were in the same oven thermostated at $70{ }^{\circ} \mathrm{C}$. The eluent was a solution of $0.1 \mathrm{M} \mathrm{LiBr}$ in $\mathrm{N}, \mathrm{N}$-dimethylformamide (DMF) filtered through a $0.45 \mu \mathrm{m}$ nylon membrane and the flow rate was fixed at $0.7 \mathrm{~mL} \cdot \mathrm{min}^{-1}$. The samples were prepared in a mixture of eluent and toluene $(0.25 \mathrm{vol} \%)$ as the flowmarker, filtered through a $0.2 \mu \mathrm{m}$ nylon filter (Interchim) and placed in an autosampler preheated at $50{ }^{\circ} \mathrm{C}$. The sample concentration was $0.25 \mathrm{wt} \%$. Calibration curves were established with poly(methyl methacrylate) (PMMA) standards purchased from Agilent. 


\subsection{Critical micellar concentration (CMC)}

The CMC was determined by hydrophobic probe method using cyanine 5.5 (Cy5.5). Samples of concentrations ranging from 0.4 to $200 \mu \mathrm{g} \cdot \mathrm{mL}^{-1}$ were prepared from a stock solution of copolymer at $200 \mu \mathrm{g} \cdot \mathrm{mL}^{-1}$. Then $20 \mu \mathrm{L}$ of Cy5.5 solution in acetone $\left(0.36 \mathrm{mg} \cdot \mathrm{mL}^{-1}\right)$ was added to $2 \mathrm{~mL}$ of each solution, and the solvent was evaporated under hood for $4 \mathrm{~h}$. Each sample spectrum was recorded from 630 to $750 \mathrm{~nm}$ by UV-visible spectroscopy Cary 50, VARIAN spectrometer. Absorbance at $680 \mathrm{~nm}$ vs. copolymer concentration curve gave the CMC at the slope break.

\subsection{Thermosensitivity}

Test tube inverting method. The solution to gel transition was determined by a modified test tube inverting method as the one previously described by Jeong et al. ${ }^{34}$. Briefly, $1 \mathrm{~mL}$ block copolymer solutions were prepared at 5 and $10 \mathrm{wt} \%$ in PBS (pH 7.4) in $5 \mathrm{~mL}$ test tubes. After equilibration at $15{ }^{\circ} \mathrm{C}$ for $20 \mathrm{~min}$, the temperature was incremented in steps of 5 to $45^{\circ} \mathrm{C}$. At each step, the samples were maintained at the designated temperature for 3 min and finally inverted. Samples were considered in gel state if no fluidity was observed after inverting the test tube for $30 \mathrm{~s}$. The syneresis was assessed by observation of the macroscopic phase separation.

Micelle size. Micelles were observed with a Zeiss GeminiSEM 500 and a MET FEI Tecnai G2. Dynamic light scattering analysis has been performed on $0.1 \mathrm{wt} \%$ copolymer solutions in PBS (pH 7.4). The hydrodynamic diameter of the micelles and their size distribution (PDI) were measured using a Zetasizer Nano ZS apparatus (Malvern, UK). After equilibration at $15^{\circ} \mathrm{C}$, the temperature was incremented in steps of 0.5 to $45^{\circ} \mathrm{C}$. For each step, an equilibration period was fixed at $3 \mathrm{~min}$ before performing 2 measurements that were then averaged.

\subsection{Mechanical properties}

Viscoelastic properties of the prepared hydrogels were studied to confirm similarities with the ones of soft brain tissues as it is known to limit inflammatory response, promote suitable neurite growth and favor stem cell differentiation into neurons 3,35. An Anton Paar Rheometer MCR 302 equipped with $25 \mathrm{~mm}$ diameter aluminum parallel disks was used. $0.6 \mathrm{~mL}$ of pentablock copolymer solutions at 5 or $10 \mathrm{wt} \%$ in PBS was charged on the inferior disk at $20{ }^{\circ} \mathrm{C}$. The solution was then heated to $37^{\circ} \mathrm{C}$ to form a hydrogel with a gap width of $0.9 \mathrm{~mm}$. The complex shear modulus, $G=G^{\prime}+i G^{\prime}$, was then measured as a function of frequency by 
dynamically shearing the hydrogel at a fixed strain of $1 \%$ over the frequency range 0.1 to $100 \mathrm{rad} . \mathrm{s}^{-1}$ at $37^{\circ} \mathrm{C}$. All measurements were performed in a dry air atmosphere.

\subsection{Degradation kinetics}

Hydrogel degradation kinetics was investigated in physiological conditions at $37{ }^{\circ} \mathrm{C}$ in $\mathrm{PBS}$ $\mathrm{pH}$ 7.4. Typically, the block copolymer (50 or $100 \mathrm{mg}$ ) was dissolved in $1 \mathrm{~mL}$ PBS in a $5 \mathrm{~mL}$ test tube and set at $37^{\circ} \mathrm{C}$ until complete gelification (i.e. 5 or $10 \mathrm{wt} \%$ copolymer concentration). Then, $2.5 \mathrm{~mL}$ of PBS pre-heated at $37^{\circ} \mathrm{C}$ was gently added on top of the gel. At different time points, $2 \mathrm{~mL}$ of the supernatant was withdrawn and carefully replaced by fresh PBS pre-heated at $37{ }^{\circ} \mathrm{C}$. The supernatants were dried and analyzed by ${ }^{1} \mathrm{H}$ NMR in presence of calibrated amount of DMF as a reference $\left(500 \mu 1\right.$ of a $3.95 \mathrm{mg} \cdot \mathrm{mL}^{-1}$ solution in $\left.\mathrm{CDCl}_{3}\right)$ and by $\mathrm{SEC}$.

\subsection{Loading of riluzole and cyanine 5.5}

Different hydrophobic compounds were encapsulated in the micelle core of the block copolymer, namely riluzole, a neuroprotective agent used in the treatment of cerebral ischemia, and Cy5.5, an imaging probe. The molecules were mixed with copolymer, either through a given volume of stock solution prepared in acetone (low loading, $0.1 \mathrm{wt} \%$ ) and solvent evaporation, or direct weighing (1-2 wt\% loadings). The hydrogels were then prepared as previously described above. The micellar encapsulation was assessed by UV measurements on the micelle solutions as compared to control solutions without drug or copolymer. Drug loading in the micelles was evaluated after dialysis at room temperature. $750 \mu \mathrm{L}$ of copolymer solution ( 5 or $10 \mathrm{wt} \%$ in PBS) and loaded with the drug were introduced in a dialysis tube (Pure-a-Lyzer, MWCO $3500 \mathrm{kDa}$ ) and dialyzed against $50 \mathrm{~mL}$ water. Water bath was changed at 1,2 and $3 \mathrm{~h}$. The water baths ( $2 \mathrm{~mL}$ ) were analyzed by UV-visible spectroscopy (Cary 50, VARIAN spectrometer) to quantify the non-encapsulated hydrophobic compound using calibration curves and the characteristic wavelengths of riluzole and Cy5.5, $265 \mathrm{~nm}$ and $689 \mathrm{~nm}$, respectively. Micellar solutions were also analyzed by spectrometry after micelle destruction (solubilization) in given volume of acetone, using a calibration established in the same conditions.

\subsection{In vitro riluzole release}

In vitro riluzole release from the hydrogel (typical drug loading: $0.1 \mathrm{wt} \%$ to copolymer) was performed in the same conditions as those used for degradation experiments $(1 \mathrm{~mL}$ of 5 or 
$10 \mathrm{wt} \%$ hydrogel, in $2.5 \mathrm{~mL}$ PBS $\mathrm{pH}$ 7.4). The released riluzole was assessed by UV analysis of the releasing PBS medium at different time points, using a calibration curve established in PBS.

\subsection{In vitro cell compatibility}

Cell culture. To determine if our hydrogel has a cytotoxic effect on neuronal cells from hippocampal structure, brains from 18-day-old rat embryos were dissected into sterile Hanks' Balanced Salt solution (HBSS) to isolate the hippocampi. Hippocampi were incubated during $15 \mathrm{~min}$ at $37^{\circ} \mathrm{C}$ using HBSS/trypsin solution prior to be mechanically crushed in order to dissociate the tissue to single cells. Neuronal cells were then plated in minimal essential medium (MEM) at a density of 200,000 cells. $\mathrm{mL}^{-1}$ supplemented with $10 \%$ NU serum (BD Biosciences, Le Pont de Claix, France), $0.45 \%$ glucose, $1 \mathrm{mM}$ sodium pyruvate, $2 \mathrm{mM}$ glutamine and $10 \mathrm{IU}$ $\mathrm{mL}^{-1}$ penicillin-streptomycin. Neuronal cells were evenly divided into 3 conditions: 1) the Control condition (solution with $0.5 \mathrm{~mL}$ of cells/MEM + serum), 2) the Hydrogel $_{50 \mu l}$ condition (solution with $0.5 \mathrm{~mL}$ of cells/MEM + serum $+50 \mu \mathrm{L}$ of hydrogel; $5 \mathrm{wt} \%$ copolymer/PBS) and 3) the Hydrogel $\mathrm{l}_{300 \mu \mathrm{l}}$ condition (solution with $0.5 \mathrm{~mL}$ of cells/MEM + serum $+300 \mu \mathrm{L}$ of hydrogel; $5 \mathrm{wt} \%$ copolymer/PBS). Three Labtek ${ }^{\circledR}$ boxes composed of 8 wells were filled by each condition solution in order to assess the cell viability with and without hydrogel at day 2, 4 and 7 days in vitro (DIV).

Immunocytochemical analysis. For each group, Labtek ${ }^{\circledR}$ boxes were stained either at 2 or 7 DIV. Hippocampal neurons were first washed by PBS 1X and fixed in Antigenfix during 20 min at room temperature prior to be permeabilized and blocked with PBS $1 \mathrm{X}$ containing $0.3 \%$ Triton $\mathrm{X}-100$ and $5 \%$ goat serum. Neurons were stained overnight at $4{ }^{\circ} \mathrm{C}$ with both rabbit anti-GFAP (1:500; MAB360, Merck Millipore) and mouse anti-MAP2 (1:1000; M9942, Sigma-Aldrich) primary antibodies and were incubated with fluorescent goat anti-mouse Alexa-Fluor-555 (1:1000; Life Technologies) and goat anti-rabbit Alexa-Fluor-488 (1:1000; Life Technologies) secondary antibodies for $2 \mathrm{~h}$ at room temperature. Cell nuclei were revealed using 5 min staining with Hoechst (1 mg.mL $\mathrm{mL}^{-1}, 33258$, stock solution used at 1:1000, Sigma-Aldrich). For quantitative analysis, images were obtained with an Olympus Fluorview-500 confocal microscope $(20 \times ; 1.0$ NA). Several images were randomly acquired and we specifically chose optical fields away from the hydrogel boundary for Hydrogel group, to avoid neuronal death related to the detachment of cells after hydrogel degradation. Neuronal morphologies were revealed with MAP2 and Hoechst 
co-labeling before been qualitatively characterized. Moreover, the cell viability was assessed by quantifying the total number of neuronal cells in each optical field at DIV 2, 4 and 7, averaged and compared between Control and both Hydrogel conditions.

\subsection{Cell ability to absorb encapsulated hydrophobic compound (Fluo-4 AM)}

Human Embryonic Kidney (HEK) cells were obtained from the American Type Tissue Culture Collection (LGC-Promochem, CRL-1573, Molsheim, France). They were grown in Dulbecco's Modified Eagle Medium (Life Technologies), supplemented with $10 \%$ fetal bovine serum (FBS, Life Technologies), $2 \mathrm{mM}$ glutamine (Life Technologies), $100 \mathrm{U}_{\mathrm{mL}}^{-1}$ penicillin and $100 \mathrm{mg} \cdot \mathrm{mL}^{-1}$ streptomycin (Sigma-Aldrich). Cells were incubated in 4 wells plate Labtek ${ }^{\circledR}$ together with $150 \mu \mathrm{L}$ of $5 \mathrm{wt} \%$ hydrogel containing $40 \mu \mathrm{g}$ of Fluo-4 acetoxymethyl (Fluo-4 AM) (F14201, Life Technologies). Images were acquired with a 10× objective using Evos FL device (Life Technologies) at 2, 4, 6 and $30 \mathrm{~h}$.

\subsection{In vivo injectability}

Animals. Three adult male Sprague Dawley rats, weighting between 250-270 g (Centre d'élevage Roger JANVIER, Le Genest Saint Isle, France), were singly housed in smooth-bottomed plastic cages in a colony room maintained on a $12 \mathrm{~h}$ light/dark cycle. Food and water were available ad libitum. The room temperature was maintained at $22{ }^{\circ} \mathrm{C}$. In order to accustom the animals to the laboratory environment, an acclimation period of 2 weeks was allowed before the initiation of the experiment. Animals were assigned to 3 different conditions, namely Hydrogel - D (day) 0, Hydrogel - D2 and Hydrogel - D7 in which the brain was respectively removed immediately (fresh brain in order to observe Cy5.5 location into the brain and needle location), 2 days or 7 days (intracardiac perfusion before performing histological analysis) after hydrogel injection.

Ethical statement. Anesthesia and surgical procedures were performed according to the French law on animal care guidelines and the Animal Care Committees of Aix-Marseille Université (AMU) and Centre National de la Recherche Scientifique (CNRS) approved our protocols. Individual conducting researches were listed in the authorized personnel section of the animal research protocol or added to a previously approved protocol (License A 13 01306). Furthermore, experiments were performed following the recommendations provided in the Guide for Care and Use of Laboratory Animals (U.S. Department of Health and Human Services, National Institutes of Health) and in accordance with the European Community's council directive of 24 November 
1986 (86/609/EEC). No clinical sign of screech, prostration and hyperactivity were observed through the study.

Surgical protocol for hydrogel injection within the striatum. Animals were anesthetized with an intraperitoneal injection of Ketamine-xylazine (100 mg. $\mathrm{kg}^{-1}$ and $10 \mathrm{mg} \cdot \mathrm{kg}^{-1}$, respectively) (Anesteo, Villetelle, France). The rat head was strongly fixed in a stereotaxic device (WPI World Precision Instruments, Hertfordshire, United Kingdom) before exposing the bregma. Striatum coordinates were determined according to Paxinos and Watson (2006): $-6 \mathrm{~mm}$ for dorsoventral axis, $3 \mathrm{~mm}$ for mediolateral axis, and $-0.12 \mathrm{~mm}$ for the rostrocaudal axis. A craniotomy $\left(2 \mathrm{~mm}^{2}\right)$ was then performed at the predefined coordinate points using a power drill (WPI ${ }^{\circledR}$, World Precision Instruments, Hertfordshire, United Kingdom). The dura was removed and a 33G needle was inserted into the striatum and $10 \mu \mathrm{l}$ of copolymer solution at $5 \mathrm{wt} \%$ in PBS saturated with Cy5.5 was injected at flow rate of $3.33 \mu \mathrm{L} \cdot \mathrm{min}^{-1}$. Before removing it, the needle remained inserted during $6 \mathrm{~min}$. The skin head was then sutured prior to subcutaneously inject $0.3 \mathrm{~mL}$ of buprenorphine ( $\left.0.05 \mathrm{mg} \cdot \mathrm{kg}^{-1}\right)$ along the prospective incision site.

Histological analysis. Two or 7 days following copolymer injection, animals were anesthetized with intraperitoneal ketamine-xylazine injection (100 mg. $\mathrm{kg}^{-1}$ and $10 \mathrm{mg} \cdot \mathrm{kg}^{-1}$, respectively) and perfused transcardially $\left(25 \mathrm{~mL} \cdot \mathrm{min}^{-1}\right)$ with $250-300 \mathrm{~mL}$ of cold phosphate buffer saline (PBS 1X), followed by paraformaldehyde $3 \%$ (antigenfix). Brain tissue was removed, post-fixed for $2 \mathrm{~h}$ at $4{ }^{\circ} \mathrm{C}$ in antigenfix, cryoprotected $24 \mathrm{~h}$ at $4{ }^{\circ} \mathrm{C}$ in $30 \%$ sucrose and then snap-frozen with isopentane and stored at $-80^{\circ} \mathrm{C}$. Coronal sections of rat brain (slide thickness: $30 \mu \mathrm{m}$; Bregma 0 to $+3 \mathrm{~mm}$ ) were performed before mounting onto Superfrost Plus glass slides. One slide of each condition (hydrogel D2 and D7) was used either for cresyl violet staining or for Cy5.5 fluorescence exposition. For cresyl violet staining, sections were rehydrated with PBS 1X and incubated in cresyl violet during $15 \mathrm{~min}$ at room temperature prior to be successively dehydrated in $70 \%$ and $100 \%$ ( $5 \mathrm{~min}$ ) ethanol. Sections were then cleaned in xylene during $10 \mathrm{~min}$. Finally, coverslips were applied onto glass slides with Fluoromount G mounting medium on slides. For qualitative analysis, images of Cy5.5 fluorescence were acquired with an Olympus Fluorview500 confocal microscope ( $4 \times ; 1.0 \mathrm{NA}$ ). In addition, to ensure appropriate hydrogel injection process into the striatum, the fresh brain was immediately removed after copolymer solution injection (i.e. Hydrogel-D0). It was sectioned using a brain slicer (2 $\mathrm{mm}$ thick) and characterized by macroscopic observation of the Cy5.5. 


\subsection{Statistical analysis}

For in vitro experiment, statistical analysis was performed using GraphPad Prism 6 Software. All data are presented in raw values, averaged in each condition and expressed as mean $\pm \mathrm{SD}$. Mean values were compared between Control, Hydrogel ${ }_{50 \mu \mathrm{L}}$ and Hydrogel ${ }_{300 \mu \mathrm{L}}$ conditions by Student's $t$-test. Post-hoc comparisons were performed with Mann-Whitney test and results were considered statistically significantly if the $p$-value $<0.05$. 


\section{Results}

\subsection{Copolymer design and synthesis}

Our symmetric pentablock copolymer relied on three compounds bringing complementary properties: PNIPAAm for the thermosensitive (i.e. injectable) character, PLA for degradability, and PEG for water retention. The copolymer was prepared through combination of ring-opening polymerization (ROP) and nitroxide-mediated polymerization (NMP) (Scheme 1). PEG diol $\left(M_{\mathrm{n}}=4000 \mathrm{~g} \cdot \mathrm{mol}^{-1}\right)$ was used as a macro-initiator for ROP of D,L-lactide. Then, terminal PLA hydroxyl functions were allowed to react with acryloyl chloride, leading to the formation of acrylated PEG-diPLA. 1,2-intermolecular radical addition (1,2-IRA) of the MAMA-SG1 alkoxyamine on the acrylate double bonds afforded the PLA-SG1 alkoxyamine which was used as initiator for NMP of NIPAAm, yielding the pentablock copolymer. ROP performed from PEG typically led to narrowly dispersed triblock copolymers $(Đ=1.03)$ with PLA compositions/molecular weights very close to those targeted as determined by ${ }^{1} \mathrm{H}$ NMR. More precisely, the integral of the proton corresponding to the PEG block (3.6 ppm) was used as a reference to confirm the proper composition of the synthesized block copolymers. After each functionalization step (acrylation and IRA) the obtained copolymers were precipitated in diethyl ether and characterized by ${ }^{1} \mathrm{H}$ NMR end group analysis for assessing nearly $100 \%$ functionalization yields, as shown in Figure 1 (see Figure S1, supporting information), and by SEC analysis in DMF (Figure S2). The obtained final chain lengths were in good accordance from those predicted (Table 1). SEC analysis evidenced good initiation of the NMP of the NIPAAm from the PLA-b-PEG-b-PLA macroalkoxyamine, and shift of the SEC traces towards higher molar masses along conversion time suggested some polymerization control (Figure S3A). Though, evolution of the $M_{\mathrm{n}}$ was not strictly linear (Figure S3B). In addition to the attractive features of SG1 based NMP over thio- and metal- based RAFT and ATRP techniques for biorelated applications, ${ }^{36}$ our synthesis approach enabled introduction in the chain, through the 1,2IRA addition of MAMA-SG1, of two carboxylic groups of interest regarding biofunctionalization perspectives (i.e. neuroactive or adhesion peptide coupling). 


\begin{tabular}{|c|c|c|c|c|c|c|}
\hline Copolymer & $\begin{array}{c}\text { Theo. } \\
M_{\mathrm{n}}\end{array}$ & $M_{\mathrm{n}}^{\mathrm{a}}$ & $M_{\mathrm{n}}^{\mathrm{b}}$ & $M_{\mathrm{w}}^{\mathrm{b}}$ & $M_{\mathrm{p}}^{\mathrm{b}}$ & $Đ$ \\
\hline PNIPAAm $_{20}$-b-PLA $14-$ b-PEG $91-b-P_{14}$-b-PNIPAAm 20 & 12600 & 12200 & 15800 & 21100 & 15800 & 1.34 \\
\hline PNIPAAm $_{40}$-b-PLA $14-$ b-PEG 91 -b-PLA 14 -b-PNIPAAm 40 & 17100 & 16200 & 11900 & 24800 & 19900 & 2.08 \\
\hline PNIPAAm $_{60}$-b-PLA $14-b-$ PEG $_{91}$-b-PLA 14 -b-PNIPAAm 60 & 21600 & 18500 & 11400 & 27300 & 26400 & 2.40 \\
\hline PEG $_{91}$-b-PLA 28 -b-PNIPAAm 120 & 21600 & 18800 & 12800 & 38600 & 25900 & 3.01 \\
\hline
\end{tabular}

Table 1. Summary of the different block copolymers synthesized in this study. ${ }^{\text {a }}$ number-average molecular weight $\left(M_{\mathrm{n}}\right)$ calculated from ${ }^{1} \mathrm{H}$ NMR using the proton signal, ${ }^{\mathrm{b}} M_{\mathrm{n}}$, ${ }^{\mathrm{c}}$ weight-average molecular weight $\left(M_{\mathrm{w}}\right)$,

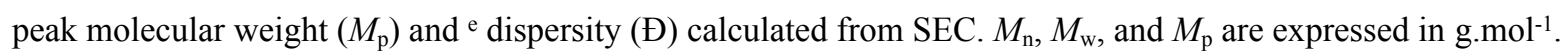

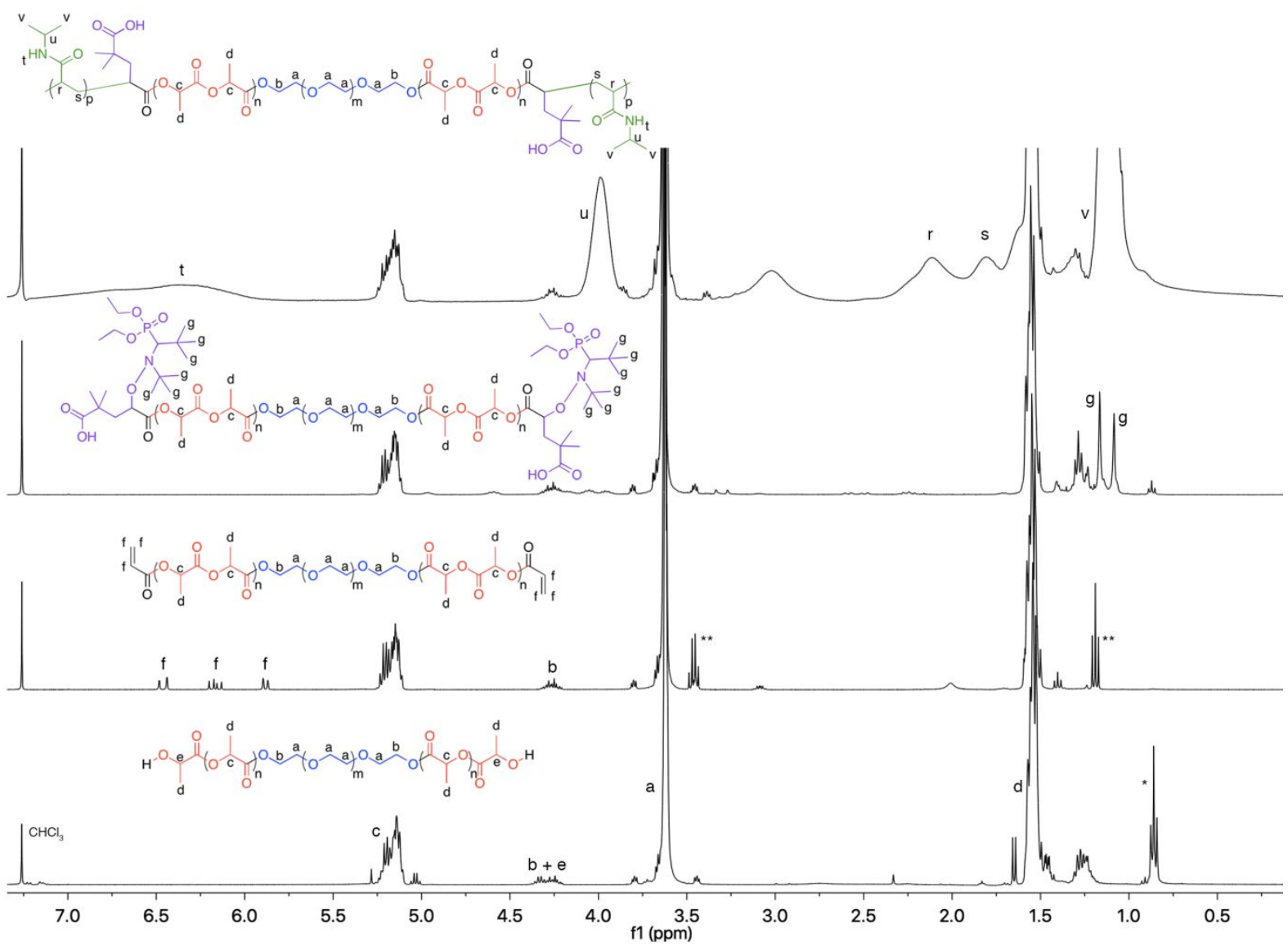

Figure 1. Modification of polymer end-groups for NIPAAm NMP monitored by ${ }^{1} \mathrm{H}$ NMR analysis. The triblock copolymer PLA-b-PEG-b-PLA (bottom) has no terminal functions while vinyl (middle, f signal) and nitroxide (top, g signal) terminal functions are present after acrylation and IRA-1,2 steps, respectively. Pentane (*) and diethyl ether $(* *)$ traces.

\subsection{Thermosensitive behavior and hydrogel formation}


Chain lengths and compositions could be finely tuned in order to optimize degradability (i.e. sufficient PLA content), gelification and water retention. A tricky point was to efficiently combine those properties. Particularly, we strived to maintain suitable water retention while introducing hydrophobic PLA. Additionally, we limited PNIPAAm length due to its biocompatibility issues, but selected sufficiently long PNIPAAm chains to induce gelification. On the basis of these prerequisites, we first synthesized pentablock with PEG of $4000 \mathrm{~g} \cdot \mathrm{mol}^{-1}$

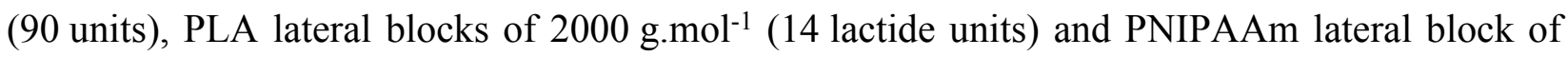
60 units (PNIPAAm $60-$ - - PLA $_{14}-$ b-PEG $91-b-$ PLA $_{14}-b-$ PNIPAAm $_{60}$ ). Due to central PEG block connecting two different PNIPAAm chains, the micellar aqueous copolymer solution was expected to gelify upon heating above the PNIPAAm hydrophilic-hydrophobic transition, through inter-micellar bridging (Scheme 2).
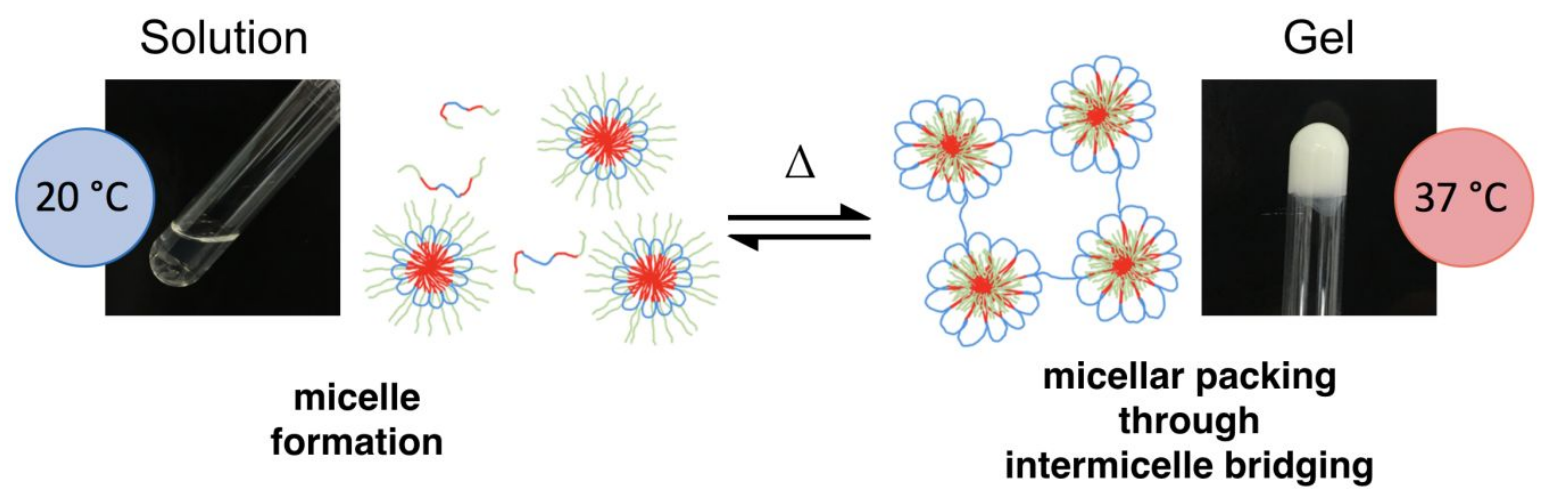

Scheme 2. Representation of the intermicelle organizations depending on the temperature. The polymer solution presents singly dispersed micelles at room temperature which from intermicelle bridging at physiological temperature.

To show the involvement of the pentablock architecture on the hydrogel formation, we synthesized as a reference a triblock PEG-PLA-PNIPAAm (PEG ${ }_{91}-$ PLA $_{28}-$ PNIPAAm $_{120}$ ) copolymer of the same composition and molecular weight using the same synthesis strategy with a methoxy-PEG-OH as initiator. First, the copolymer amphiphilic behavior was assessed through determination of the CMC by probe encapsulation method. As a probe, we used Cy5.5 dye, as a potent imaging agent that was planned to be tested in further biological studies. The CMC of the pentablock was similar in water and in physiological saline solution (i.e. $\mathrm{NaCl} 0.15 \mathrm{M}$ ), with a value of about $30 \mu \mathrm{g} \cdot \mathrm{mL}^{-1}$ (Figure 2, left). It is interesting to note that, besides strong absorbance increase, the encapsulation of the dye provoked a shift of the $\lambda_{\max }$ towards higher wavelengths as 
a result of environment change of the dye ${ }^{37}$ (i.e. from $678 \mathrm{~nm}$ in aqueous medium, to $688 \mathrm{~nm}$ in micelle core, see arrows in Figure 2, right). CMC was also determined by the DLS dilution method, ${ }^{38,39}$ and was in very good accordance with that obtained with the Cy5.5 probe (Figure $\mathrm{S} 4$ ). The CMC of the triblock copolymer analog was similar to that of the pentablock (Figures 2 and S4). However, mean size of the micelles determined by DLS (above CMC) was smaller for the pentablock copolymer $(\sim 22 \mathrm{~nm})$ than for the triblock analog $(\sim 70 \mathrm{~nm})$, indicating a different self-assembly conformation, most probably due to the more strained pentablock architecture with its two hydrophobic PLA blocks on the same polymer chain, as well as two PNIPAAm segments, two-fold shorter each than the PNIPAAm block in the triblock structure. SEM and TEM observations of pentablock micelles at room temperature (Figures S5, A and B) indicated homogeneous distribution of spherical objects (with presence of some aggregates) and roughly corroborated the size observed by DLS.
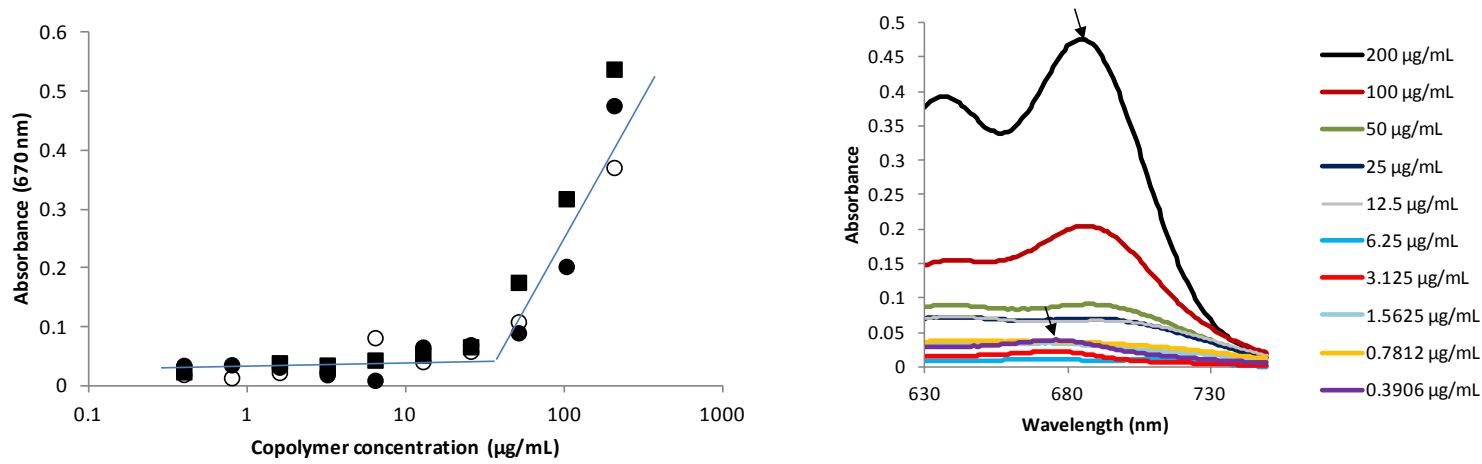

Figure 2. CMC of the copolymers: pentablock either in water (filled rounds) or in $\mathrm{NaCl} 0.15 \mathrm{M}$ (empty rounds), and triblock analog in water (filled squares) (left). Cy5.5 dye spectrum in presence of different concentrations of copolymer solution (right).

Hydrogel formation upon heating copolymer solutions at 5 or $10 \mathrm{wt} \%$ in physiological medium (PBS or $\mathrm{NaCl} 0.15 \mathrm{M}$ ) was followed by the test tube inverting method. Hydrogel formation occurred for the pentablock copolymer solution, contrary to triblock analog, which remained liquid while becoming turbid upon heating (Figure 3). The formation of the hydrogel for the pentablock copolymer occurred around $30^{\circ} \mathrm{C}$, a suitable temperature for in vivo injectability (i.e. convenient handling as a liquid at room temperature and gelation below $37{ }^{\circ} \mathrm{C}$ ). Interestingly, decreasing the PNIPAAm blocks to 40 and 20 lateral units still allowed hydrogel formation at $10 \mathrm{wt} \%$ in PBS (Table 1, Figure S6). However, the copolymer with the shortest PNIPAAm blocks led to a very viscous solution at room temperature which was unsuitable for 
the targeted application. Additionally, more pronounced water expulsion was observed upon storage at $37{ }^{\circ} \mathrm{C}$ when PNIPAAm blocks were shorter. This result is probably due to insufficient entanglement of PNIPAAm segments in the PNIPAAm crosslinking domains, resulting in demixing (Figure S2). In any case, for the first time to our knowledge, copolymers of moderate to low amounts of PNIPAAm (63-38 wt\%) and significant degradable PLA content (16-29 wt\%) were able to turn into hydrogels at physiological temperatures. In addition, with the chosen maximum average DP of 60 , namely a $\mathrm{Mn} \sim 7 \mathrm{kDa}$, PNIPAAm chains recovered after copolymer degradation are far below the commonly admitted polymer cutoff of $\sim 40 \mathrm{kDa}^{40-42}$ (even the longest chains arising from the moderate dispersity 2), thus prone to ensure renal clearance.

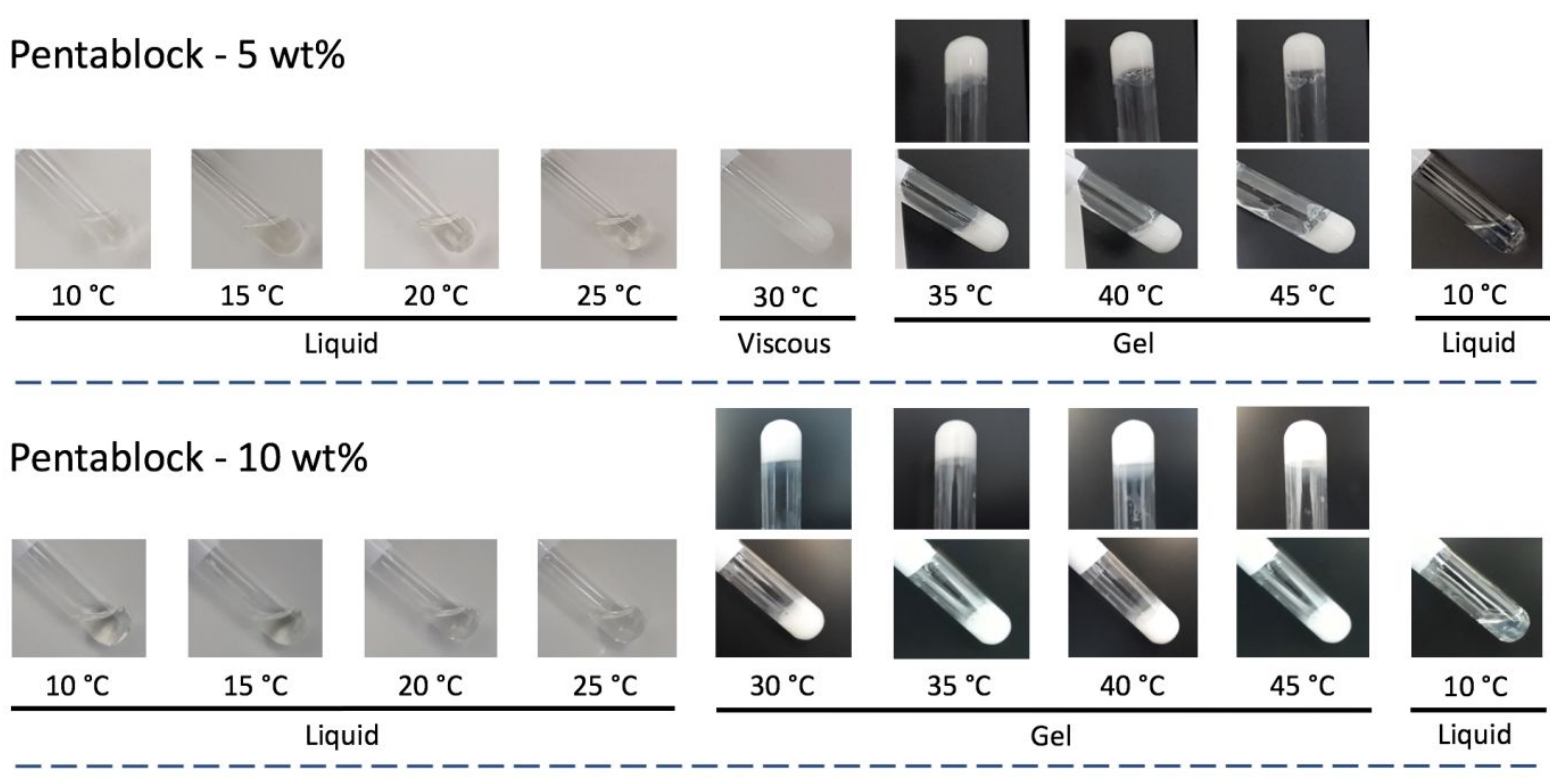

Triblock - 10 wt\%

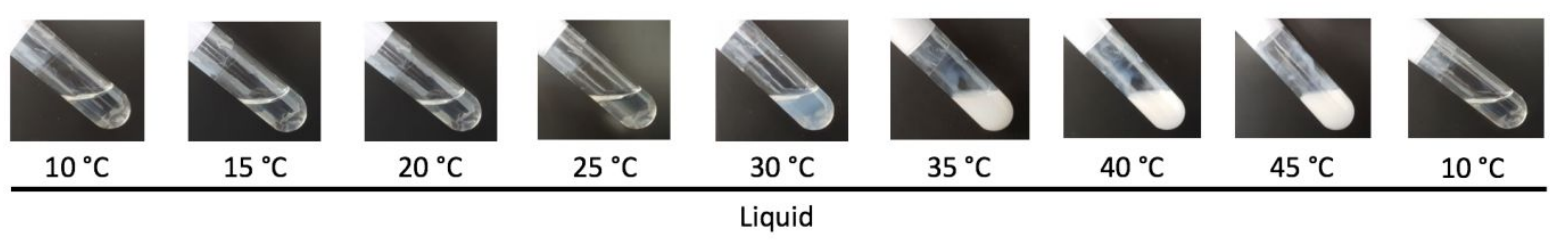

Figure 3. $5 \mathrm{wt} \%$ (top) and $10 \mathrm{wt} \%$ (middle) solutions gelify in PBS at approximately $30{ }^{\circ} \mathrm{C}$. While the $5 \mathrm{wt} \%$ sample is viscous at $30{ }^{\circ} \mathrm{C}$ and the $10 \mathrm{wt} \%$ can be readily inverted without flowing. Contrary to the pentablock architecture, the triblock copolymer (bottom) is unable to gelify in PBS at $10 \mathrm{wt} \%$ whatever the temperature. All the studied hydrogels are reversible as they turned back to transparent solutions at lower temperatures. 
The gelation process was more deeply investigated by monitoring the mean size of micellar solution vs. temperature in the range of $15-45^{\circ} \mathrm{C}$ (Figure 4). Pentablock copolymer solutions ( $0.1 \mathrm{wt} \%$ in PBS) showed micellar state from 15 to $27.5^{\circ} \mathrm{C}$, with mean sizes of about $22 \mathrm{~nm}$. From this temperature on, a continuous and dramatic increase in size was observed until reaching a value of about $6000 \mathrm{~nm}$ at $35^{\circ} \mathrm{C}$, evidencing the intermicellar aggregation process. Thereafter, the size decreased from $35^{\circ} \mathrm{C}$ to $45^{\circ} \mathrm{C}$ probably due to the sedimentation of these large aggregates. In contrast, the DLS analysis performed on the triblock analog showed a very different behavior. More precisely, micelles of about $\sim 70 \mathrm{~nm}$ in mean size were present from $15^{\circ} \mathrm{C}$ until $31.5^{\circ} \mathrm{C}$, a temperature from which only a slight increase in size was observed (i.e. up to $150 \mathrm{~nm}$ at $35^{\circ} \mathrm{C}$ ). This increase in size was due to the rearrangement of the nano-objects, as PNIPAAm segment switched from hydrophilic (corona localization) to hydrophobic (core localization), but no macroscopic aggregation occurred as observed with the pentablock structure. It is also interesting to note that, despite the same copolymer composition, the triblock copolymer's LCST was closer to the one of the PNIPAAm homopolymer $\left(32{ }^{\circ} \mathrm{C}\right)$ than the pentablock. Such result is presumably due to a lower strain of the PNIPAAm segment in the triblock structure. These results strongly corroborated the tube inverting method, and clearly showed that pentablock architecture was responsible for hydrogel formation through intermicellar bridging.

The storage and loss modulus G' and G' of the pentablock hydrogel were finally evaluated by rheological measurements for both 5 and $10 \mathrm{wt} \%$ copolymer concentrations at $37^{\circ} \mathrm{C}$ (Figure S7). Both G' and G" values increased with the angular frequency ranging from 0.1 to $100 \mathrm{rad}_{\mathrm{s}} \mathrm{s}^{-1}$. As expected, G' and G' values of the $5 \mathrm{wt} \%$ copolymer solution ( $\mathrm{G}$ ' from 15 to $270 \mathrm{~Pa}$ and $\mathrm{G}$ " from 12 to $135 \mathrm{~Pa}$ ) were inferior to the ones of the $10 \mathrm{wt} \%$ sample (G' from 120 to $1900 \mathrm{~Pa}$ and G" from 90 to $600 \mathrm{~Pa}$ ). These values typically matched with those of brain tissue. The $5 \mathrm{wt} \%$ copolymer hydrogel was further selected for intracerebral injections, due to its most appropriate modulus (i.e. lowest) ${ }^{43}$, and thus proneness to avoid potential inflammation responses ${ }^{44}$. 


\subsection{Hydrophobic biomolecule loading}

As formation of the hydrogel occurred from micellar solutions, it allowed loading of hydrophobic molecules by encapsulation in the micellar core by simple mixing of the molecule with the copolymer at room temperature. Cy5.5 as imaging probe (for further hydrogel in vivo tracking) was first used at $0.1 \mathrm{w} \%$ compared to copolymer (10 $\mathrm{wt} \%$ in $\mathrm{NaCl} 0.15 \mathrm{M}$ or PBS). The micellar solubilization effect could be clearly evidenced as compared to Cy5.5 alone and copolymer alone used as controls in the same concentration conditions (Figure 5, top). No Cy5.5 absorption was detected in the purification baths used for the dialysis of the Cy5.5-loaded micelle solution at room temperature, indicating $100 \%$ encapsulation (i.e. $0.1 \mathrm{wt} \%$ molecule loading). Visually, the Cy5.5 remained homogenously distributed in the matrix following hydrogel formation. Moreover, following decrease to room temperature, the absorbance measured was the same than before gel formation, assessing the reversibility of the process. The Cy5.5 encapsulation was further investigated at high loading (i.e. $2 \mathrm{wt} \%$ with respect to copolymer, saturating conditions). Precipitated probe was observed in the bottom of the tube (Figure S8), and visible spectrometry assay of the probe in the homogeneous solution (after solubilization of micelles in acetone) showed a $0.75 \mathrm{wt} \%$ loading, i.e. $38 \%$ encapsulation yield. Interestingly, even at this high loading, the Cy5.5 did not alter the gel formation (Figure S8). Furthermore, the Cy5.5 remained homogenously distributed in the forming hydrogel, again indicating that intermicellar bridging process did not induce release of the molecule in the external aqueous phase. 
Loading of riluzole, as a clinically advanced neuroprotective drug in neural tissue engineering perspective, was then investigated. The drug was mixed at $1 \mathrm{wt} \%$ compared to copolymer (10 wt\% in PBS). Increased riluzole-water solubility through micelle encapsulation was observed from UV spectrometry, as compared to riluzole alone as control in same concentration (Figure 5, bottom). Unencapsulated drug was removed by dialysis against water and quantified by UV analysis in the dialysis baths using a riluzole calibration curve (absorbance vs. concentration, $0-20 \mu \mathrm{g} \cdot \mathrm{mL}^{-1}$ range, within the linear domain). The encapsulation yield of $96 \%$ (i.e. $0.96 \mathrm{wt}^{\%} \%$ drug loading) indicated that despite a non-negligible water solubility, riluzole drug was almost completely located in the micelles.
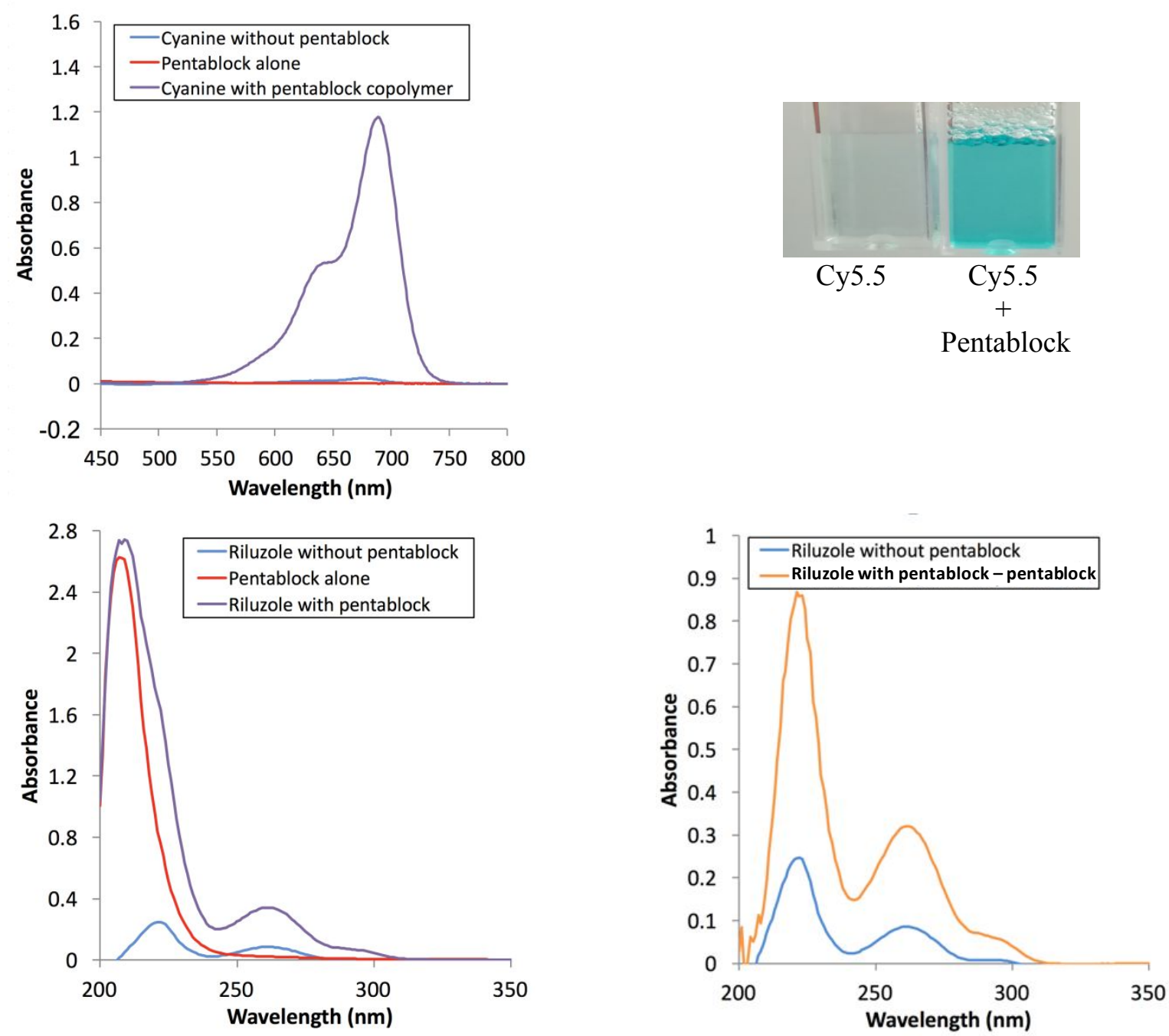

Figure 5: UV-visible absorption of hydrophobic compounds after micellar encapsulation. Cy5.5 absorption (top, left, 13.3-fold dilution of Cy5.5/copolymer solution at $0.1 \mathrm{mg} \cdot \mathrm{mL}^{-1} / 100 \mathrm{mg} \cdot \mathrm{mL}^{-1}$ ). Photograph of cuvette containing Cy5.5 in physiologic saline solution with and without block copolymer (top, right). Riluzole 


\begin{abstract}
absorption with and without block copolymer (bottom, left, 100-fold dilution of riluzole/copolymer solution at $1 \mathrm{mg} \cdot \mathrm{mL}^{-1} / 100 \mathrm{mg} \cdot \mathrm{mL}^{-1}$ ), and after subtracting the copolymer blank spectrum (bottom, right).
\end{abstract}

\title{
3.4 in vitro degradation and drug release
}

Degradation of hydrogels formed at 5 and $10 \mathrm{wt} \%$ copolymer in PBS was investigated in physiological conditions at $37^{\circ} \mathrm{C}$ in PBS pH 7.4. The same conditions than those further used for drug release ( $1 \mathrm{~mL}$ of hydrogel in $2.5 \mathrm{~mL}$ PBS) were investigated, to assess the contribution of degradation on the release process. The hydrogels gradually eroded until complete disappearance, yielding a final homogeneous, slightly turbid solution a $37{ }^{\circ} \mathrm{C}$, with kinetics dependent on the polymer concentration (Figure 6A). Polymer mass loss over time was quantitatively assessed by ${ }^{1} \mathrm{H}$ NMR analysis of the releasing media (after freeze-drying) at various times through integration using an internal standard (DMF, $8 \mathrm{ppm}$ ), and clearly evidenced the impact of the polymer concentration on the erosion kinetics (Figure 6B, Figure S9 for the NMR spectra). 
A

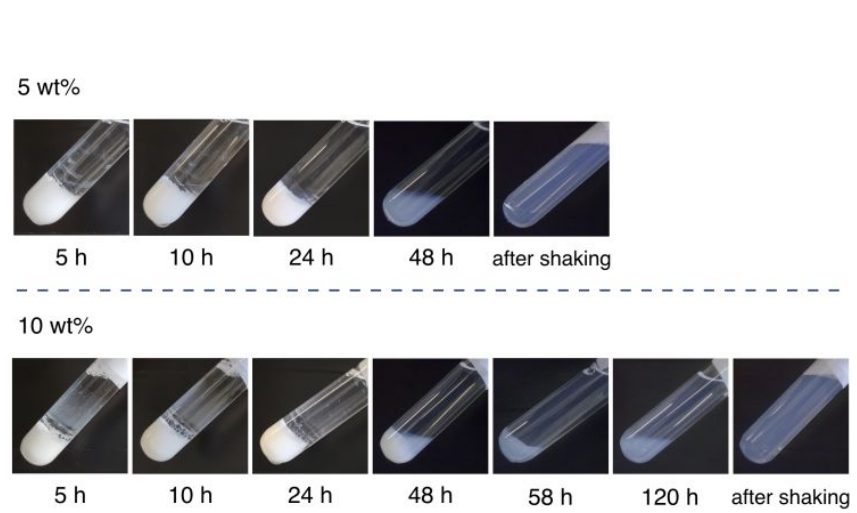

B

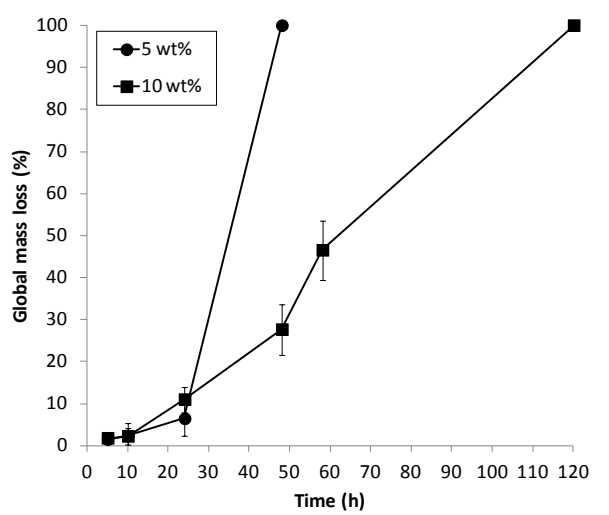

Figure 6. Degradation assessed visually (A, photographs) and quantitatively (B, ${ }^{1} \mathrm{H}$ NMR) of the pentablock copolymers at $5 \mathrm{wt} \%$ (top) and $10 \mathrm{wt} \%$ (bottom) maintained at $37^{\circ} \mathrm{C}$ in PBS.

We further investigated more deeply the mechanism underlying this erosion process, first through ${ }^{1} \mathrm{H}$ NMR analysis of the whole dispersion (after freeze-drying) obtained after total erosion ( $40 \mathrm{~h}$ for the $5 \mathrm{wt} \%$ hydrogel, Figure $7 \mathrm{~B}$ ). The spectra showed significant presence of the proton signals characteristic of the methine protons $(\mathrm{d}, \mathrm{e})$ adjacent to the $\mathrm{OH}$ and $\mathrm{COOH}$ lactide end groups ( 4.85 and $4.25 \mathrm{ppm}$, respectively), as compared to the initial intact block copolymer (presenting only $-\mathrm{CH}$ - lactide proton signals, $5.2 \mathrm{ppm}$ ). This evidenced the hydrolysis of the ester bonds in the lactide block, leading to pentablock cleavage. The latter was confirmed by SEC analysis indicating a peak shift toward lower molecular weights (Figure S10). Considering the integration ratio between these end group methine protons and the unaffected lactide methine ones $(\sim 1 / 10)$, and that one PLA segment contains 28 methine protons in average, it could be assumed that this hydrolysis affected at least both lactide segments in the pentablock, thus yielding breaking of the PEG bridges and thus formation of PEG di- oligolactide and free micelles (containing some PNIPAAm-oligolactide residues). As a result, the network broke, resulting in compound diffusion outside the hydrogel and final homogeneous dispersion. Further ${ }^{1} \mathrm{H}$ NMR analysis at later degradation times on the dispersion $(\sim 100 \mathrm{~h})$ showed amplification of PLA degradation (Figure 7C for ${ }^{1} \mathrm{H}$ NMR, Figure S10 for SEC), and thus increasing formation of homo-oligolactide residues. Size measurements on this slightly turbid dispersion at $37^{\circ} \mathrm{C}$ in the same conditions as those used before degradation $(0.1 \mathrm{wt} \%$ in PBS) showed presence of nanoparticles of $40 \mathrm{~nm}$ mean size $(\mathrm{PDI}=0.09)$, again supporting the particulate cross-linking 
nature of our hydrogel. Interestingly, further monitoring the thermoresponsive behavior of this dispersion from 15 to $40{ }^{\circ} \mathrm{C}$ (similarly as performed before degradation) showed again nanoobjects of about $23 \mathrm{~nm}$ at $15^{\circ} \mathrm{C}$ and until $30{ }^{\circ} \mathrm{C}$ (Figure S11). However, above this temperature, no macroscopic aggregation occurred, but only a slight increase in size (to $40 \mathrm{~nm}$ ) due to PNIPAAm transition, clearly showing that the pentablock structure had been cleaved, making the intermicellar bridging process impossible.
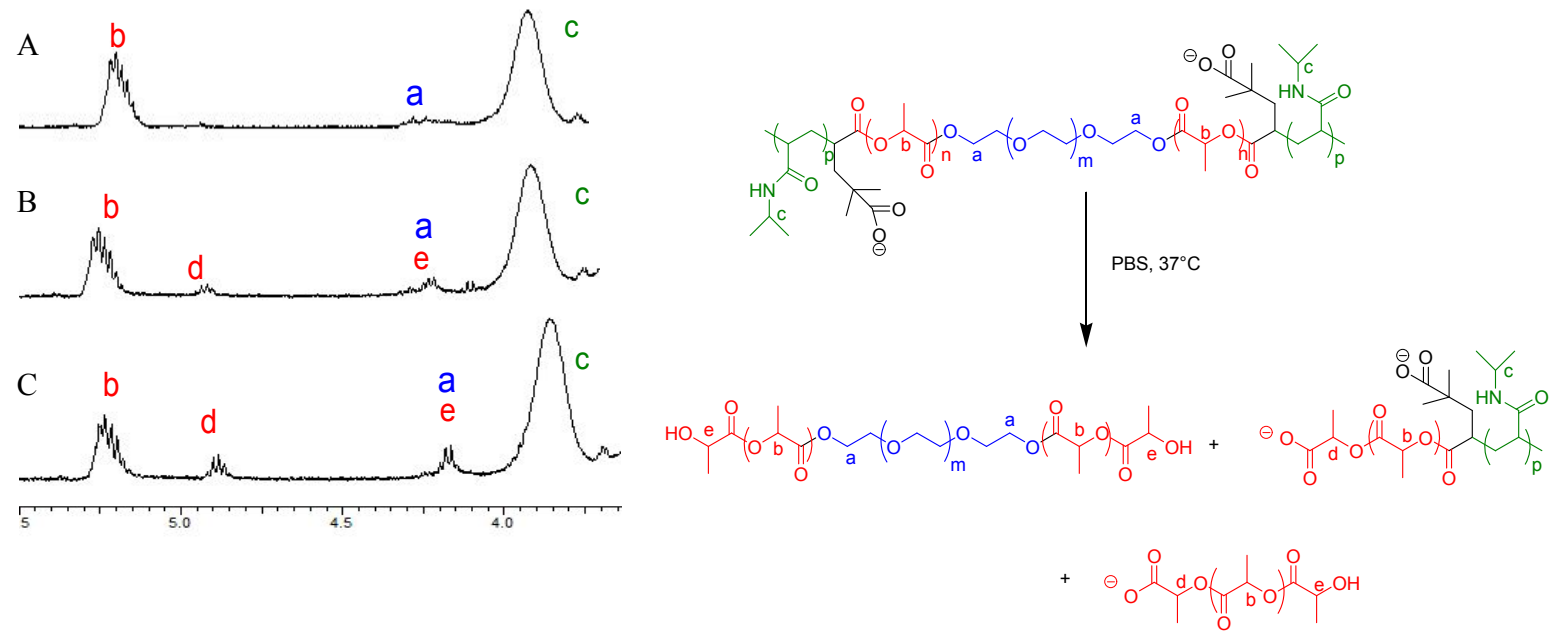

Figure 7. ${ }^{1} \mathrm{H}$ NMR analysis (DMSO- $\mathrm{d}_{6}, 3.5-5.5 \mathrm{ppm}$ ) of the $5 \mathrm{wt} \%$ hydrogel after $40 \mathrm{~h}(\mathrm{~B})$ and $115 \mathrm{~h}(\mathrm{C})$ in PBS pH 7.4, $37^{\circ} \mathrm{C}$, as compared to reference copolymer (A). 
When loaded with riluzole drug $(50 \mu \mathrm{g}$, i.e 0.1 and $0.05 \mathrm{wt} \%$ to copolymer, for 5 and $10 \mathrm{wt} \%$ hydrogels, respectively) in the same conditions, the hydrogels degraded/disappeared through the same kinetics upon hydrolysis than the non-loaded hydrogel. The released drug over time was quantified in the releasing medium by UV analysis. Our in vitro conditions ensured nonsaturating conditions (i.e. maximum concentration of riluzole in releasing medium of $20 \mu \mathrm{g} \cdot \mathrm{mL}^{-1}$, at which riluzole is still soluble). No burst effect was observed. Interestingly, the micellemediated release of riluzole from the hydrogel was dependent on the polymer concentration in hydrogel and highly correlated to the polymer mass loss (Figure 8 vs. Figure 6). Finally, as riluzole was shown to be still quasi totally encapsulated at $1 \mathrm{wt} \%$ loading (96\% encapsulation yield), the release was studied in these loading conditions for the $5 \mathrm{wt} \%$ hydrogel. $25 \mathrm{~mL}$ (i.e. 10 fold-more) PBS medium were used in that case, to ensure non-saturating conditions of releasing riluzole. In these conditions, in absence of drug, the degradation of the polymer was similar to that observed in 10-fold less PBS volume. The release profile of the riluzole was also highly similar to that observed for $0.1 \%$ loading, again correlating with the polymer mass loss. In context of neural tissue engineering, the riluzole release profile was appropriated, as neuroprotective effect is expected in early times ${ }^{45}$. More generally, these results showed the opportunity to potentially tune the release of any drug through introduction of other more/less cleavable esters.

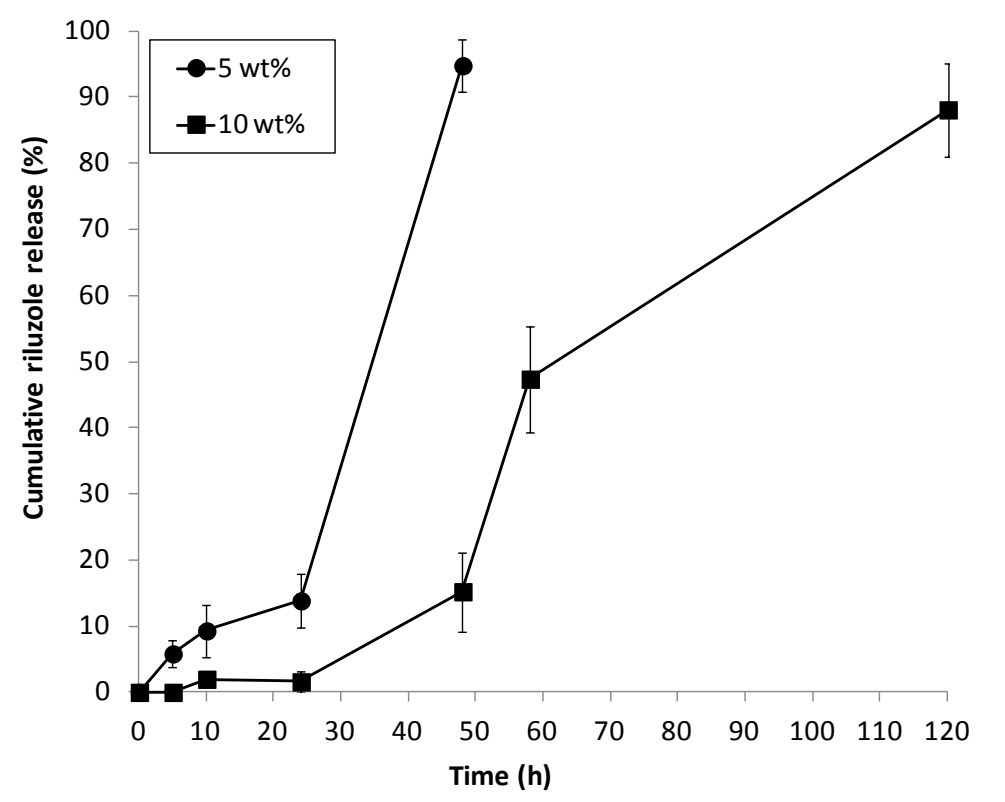


Figure 8. Cumulative riluzole release (\%) for hydrogel at 5 and $10 \mathrm{wt} \%$ in PBS.

\subsection{In vitro neural cell compatibility}

Before infusing brain tissue in vivo, it was needed to investigate the impact of the pentablock copolymer on neurons viability and development in order to ensure that hydrogel implantation will not compromise neuroplasticity processes. According to in vitro analysis, we observed numerous cell bodies and the emergence of several dendrites as reflected by the MAP2/Hoechst co-labelling in Control condition 2 days after cell cultures (Figure 9A) as previously observed in culture $^{46}$. Similar hippocampal arborization were obtained in the Hydrogel condition at day 2 after complete disappearance of the hydrogel (Figure 9B). Seven days after cell plating, MAP2 staining revealed longer neurites in the Hydrogel condition than the ones observed at day 2 in both Control and Hydrogel conditions (Figure 9C, 9D). Therefore, the degradation products of our hydrogel did not seem to impede neuronal development. In addition at the considered time of analysis (e.g DIV 2, 4 and 7), the number of hippocampal neurons is not significantly reduced in Hydrogel $_{50 \mu 1}$ condition compared to Control group at DIV 2, 4 and 7 (Figure 10A, B, C). It suggested that our copolymer and its degradation residues are not toxic for neurons at this dose. In addition, the Hydrogel $_{300 \mu 1}$ reduced the number of cells at DIV 7 only compared to Control condition at DIV $7(\mathrm{p}<0.01$; Figure 10D, E, F). Such results might indicate that hydrogel could be toxic at higher doses. Nevertheless, we can also suppose that the high hydrogel volume might dilute the culture medium resulting in a change in osmolarity that could explain cell death in such culture condition. However, it should be kept in mind that, for in vivo experiment, brain hydrogel implantation should not exceed a volume of 5-10 $\mu 1$ to avoid harmful mechanical pressure on cerebral tissues. Our results were thus encouraging because neuron disturbances should be strongly limited after hydrogel injection into the brain. Finally, these findings were in agreement with previous studies indicating that both PEG and PLA are FDA approved and used in pharmacological applications 21,47. Additionally, PNIPAAm, commonly used in tissue engineering, was shown to be non-cytotoxic to several cell types assessed in a direct contact test 48. Further studies are now required to investigate the neurodevelopment of neurons in culture and the neuroplasticity processes following brain disorders after hydrogel implantation. 

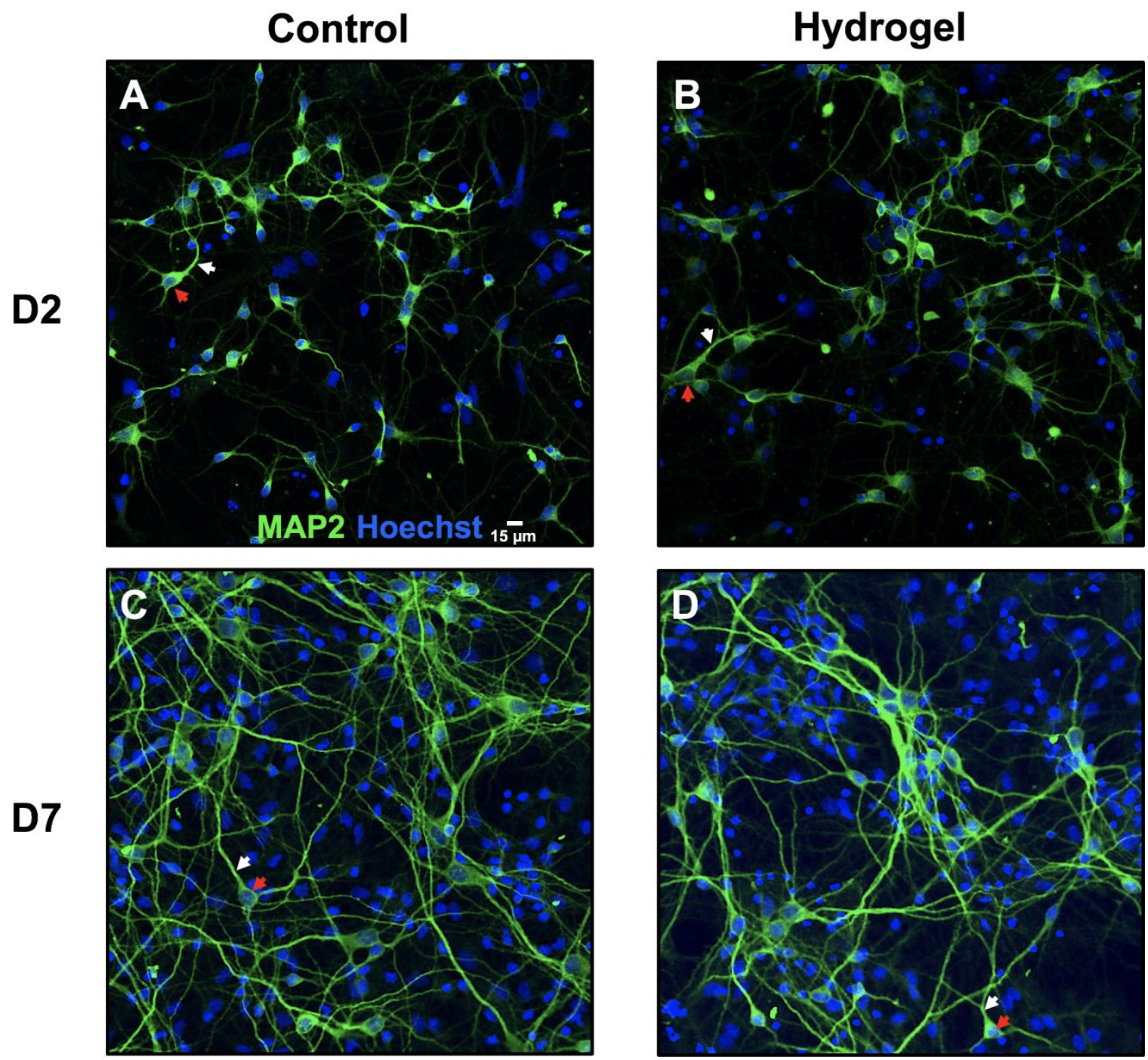

Figure 9. Toxicity evaluation of the pentablock copolymer through hippocampal neuronal cultures. (A, B) MAP2 (green) staining co-labelled with Hoechst (blue) revealed the existence of cell bodies (red arrow) as well as the emergence of dendrites (white arrow) at day 2 in the Control and the Hydrogel groups respectively. (C,D) Longer dendrites are observed for these two groups at DIV 7 compared to DIV 2. 
A
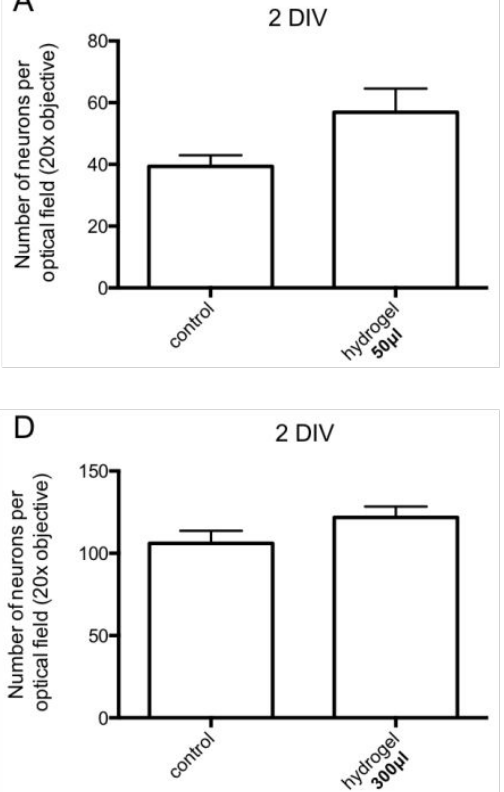
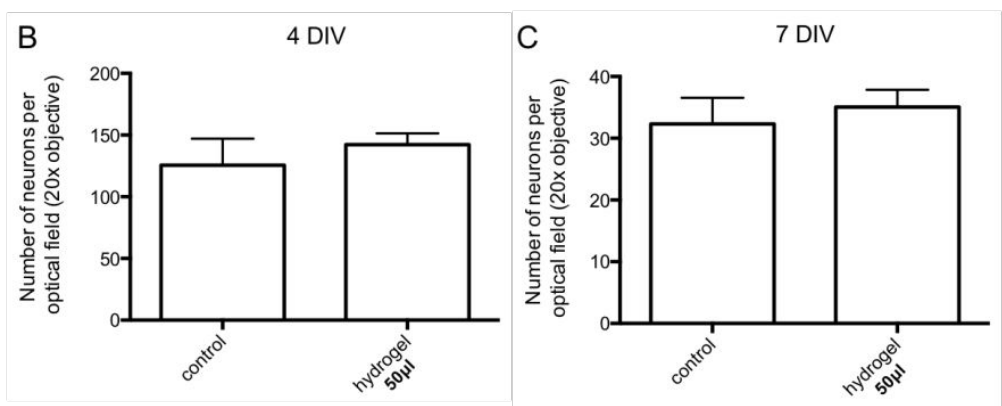

$E$
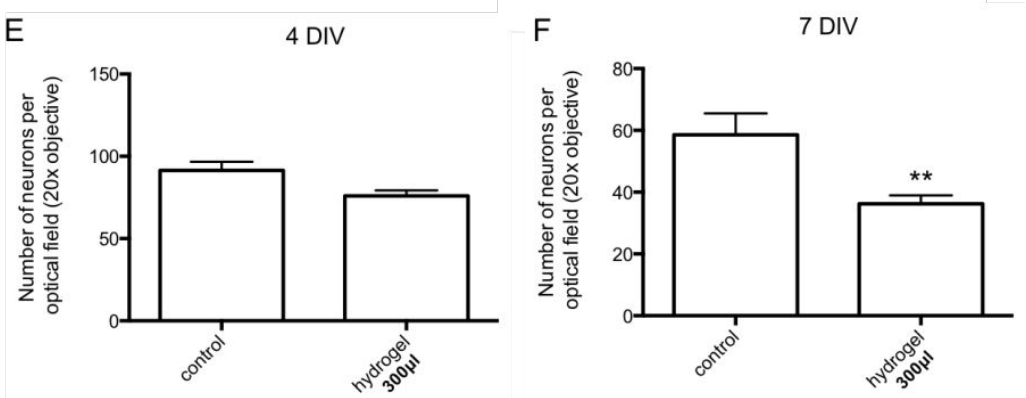

Figure 10. Impact of the pentablock copolymer on hippocampal neurons survival in culture. (A, B and C) With a $50 \mu \mathrm{l}$ volume of hydrogel, the number of neurons is not reduced at days in vitro.(DIV) 2, 4 and 7 compared to Control. (D and E) Similar results are observed at DIV 2 and 4 with a higher hydrogel volume (300 $\mu \mathrm{l})$. (F) At DIV 7, the number of cells is significantly reduced in the Hydrogel $_{300 \mu l}$ condition.

\subsection{Cell ability to absorb encapsulated hydrophobic compound (Fluo-4 AM)}

Releasing drug locally in a controlled fashion represents a major advantage of hydrogel-based approach compared to systemic or local drug injection into the brain alone. Indeed, as the hydrogel does not disperse, the drug is solely released in its vicinity. In order to assess our hydrogel capacity to release hydrophobic compound (as riluzole), Fluo-4 AM was used as a study model. Contrary to riluzole, Fluo-4 AM cell absorption can be easily observed as it is a fluorescent $\mathrm{Ca}^{2+}$ indicator (when hydrolyzed). Without hydrogel encapsulation, $20 \mathrm{~min}$ are usually waited so as to allow for complete cell internalization and de-esterification of AM esters by intracellular esterases ${ }^{49,50}$. Once encapsulated in our hydrogel, no fluorescence was detected during the first $6 \mathrm{~h}$ indicating that the fibroblast cells have not absorbed fluo4-AM and thus that the drug release did not start (Figure 11). This result confirmed that there was no burst release as reported in in vitro analysis performed in PBS with riluzole. However, the fluorescence of fibroblast cells detected at $30 \mathrm{~h}$ indicated that the drug was progressively released with a delay and incorporated into the cells. The drug release kinetic appeared to be related to the disappearance time of the pentablock copolymer. Although this result did not allow us to 
conclude if the fluo-4 AM encapsulated into the micelle was fully incorporated into the cells, it confirmed that the released substance could be efficiently internalized into brain cells.

$2 \mathrm{~h}$
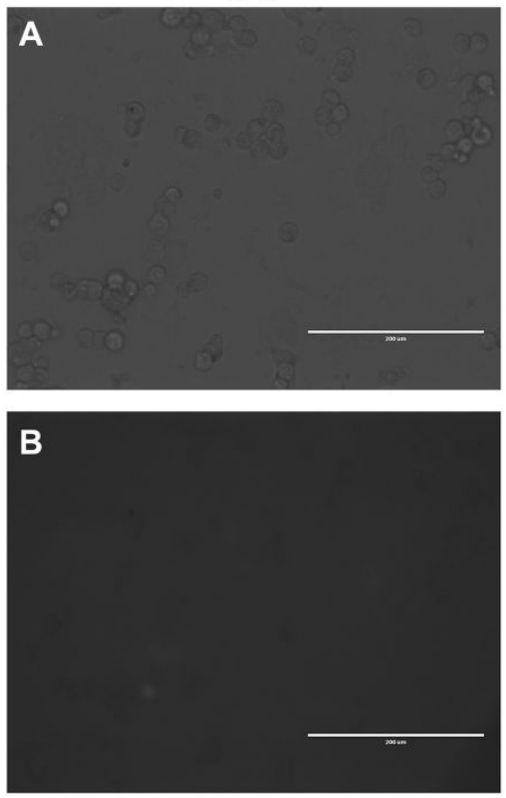

$6 \mathrm{~h}$
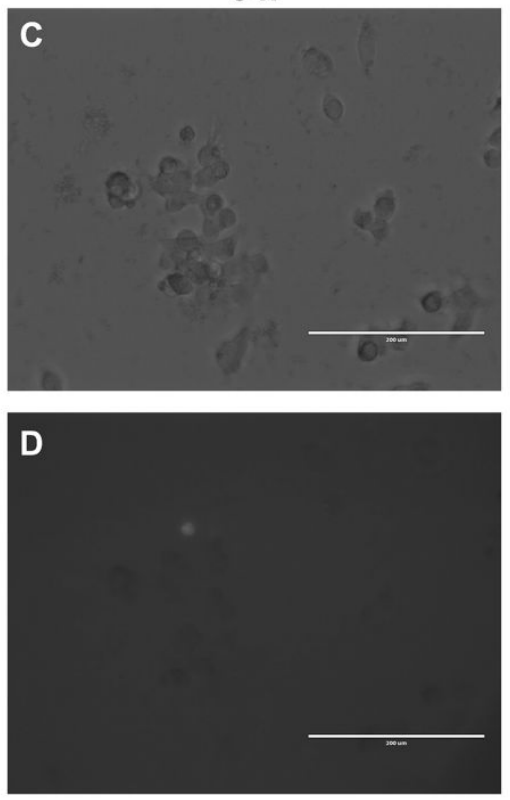

$30 \mathrm{~h}$
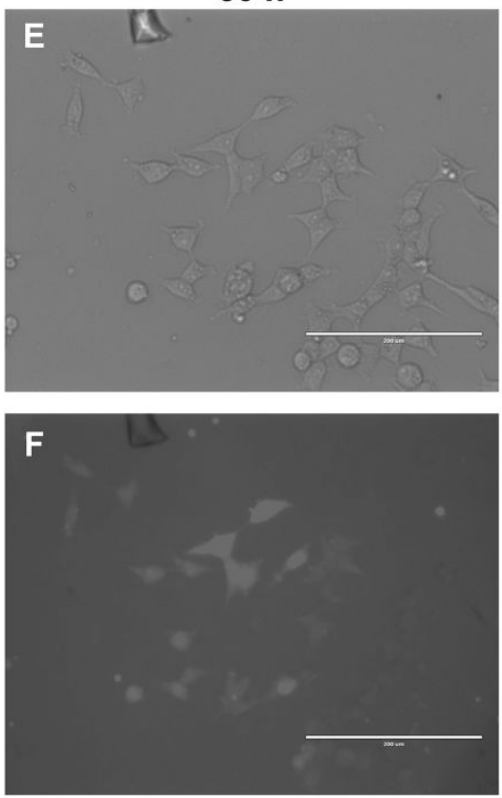

Figure 11. Fluo4-AM release by the pentablock copolymer and $\mathrm{Ca}^{2+}$ absorption of fibroblast cells at $2 \mathrm{~h}(\mathrm{~A}, \mathrm{~B})$, $6 \mathrm{~h}(\mathrm{C}, \mathrm{D})$ and $30 \mathrm{~h}(\mathrm{E}, \mathrm{F})$ post-hydrogel application; top and bottom images are microscopy without and with fluorescence, respectively (scale bar: $200 \mu \mathrm{m}$ ). No fluorescence of the fibroblast cells was detected at $2 \mathrm{~h}$ and $6 \mathrm{~h}$ while a clear absorption was observed after $30 \mathrm{~h}$

\subsection{In vivo injectability}

In hydrogel-based therapies, the capacity of a given hydrogel to be injectable constitutes an important part of its clinical relevance in order to prevent invasive and repetitive implantation procedure. We thus assessed in vivo injectability of the pentablock copolymer into the striatum which is an area frequently impacted by neurological pathologies such as stroke injury ${ }^{51}$. Immediately after injection (D0), we could observe the presence of the hydrogel with encapsulated Cy5.5 in the fresh brain section (Figure 12A). The hydrogel self-gelification thus seemed to be effective in the brain at body temperature $\left(37-38^{\circ} \mathrm{C}\right)$. This result also indicated that injection parameters $\left(33 \mathrm{G}\right.$ needle, flow rate $\left.0.33 \mu \mathrm{L} \cdot \mathrm{min}^{-1}\right)$ appeared to be suitable for hydrogel injectability. Moreover, according to the Rat Atlas brain ${ }^{52}$, hydrogel was correctly injected into the striatum and remained localized in this area (Figure 12). This observation was confirmed by cresyl violet-stained brain sections at D2 onto which a darker spherical shape characteristic of the hydrogel was identified at the striatum location (Figure 12B). After 7 days post-injection, both cresyl violet staining and Cy5.5 fluorescent detection revealed a similar stain localized around the 


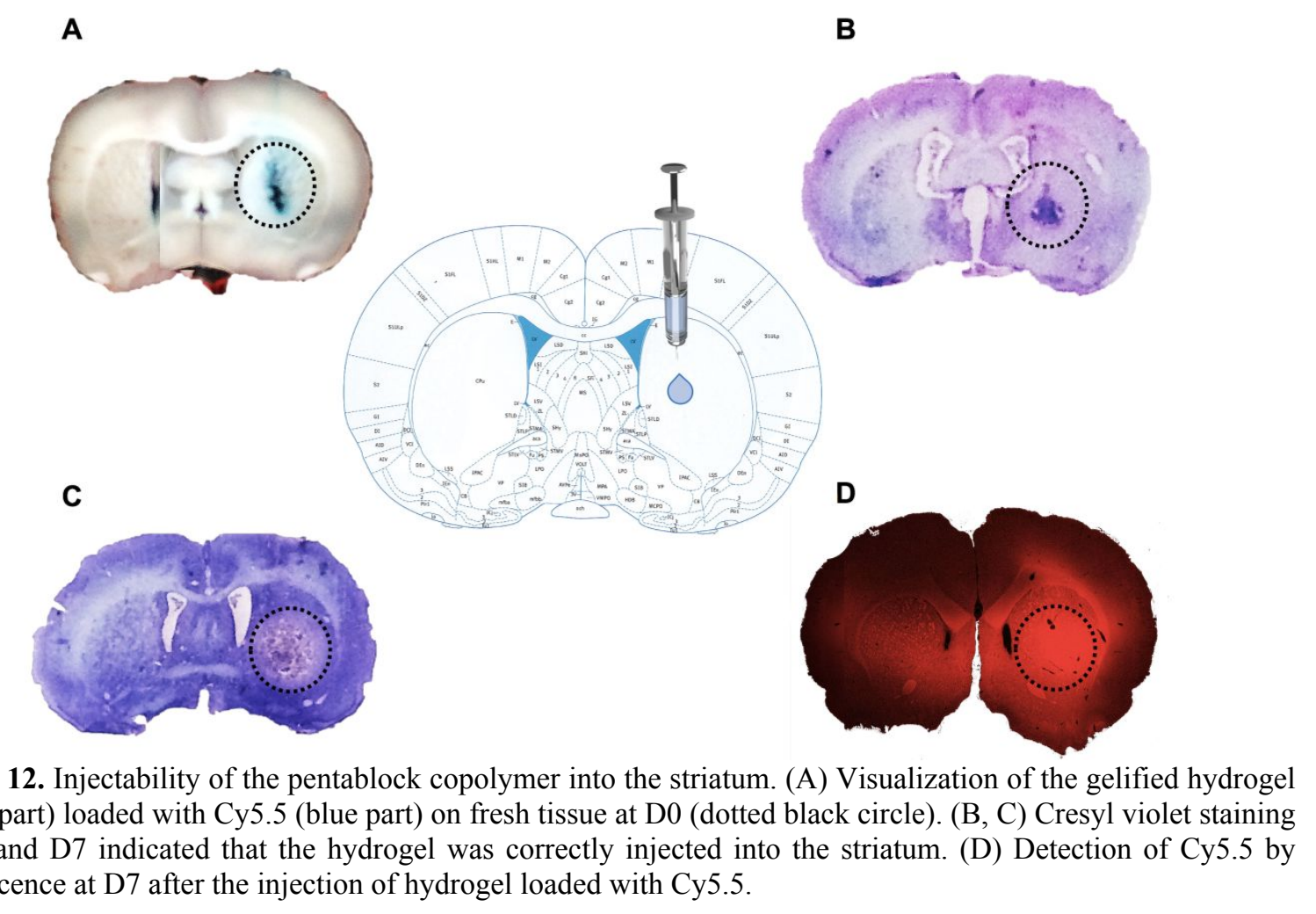

Figure 12. Injectability of the pentablock copolymer into the striatum. (A) Visualization of the gelified hydrogel (white part) loaded with Cy5.5 (blue part) on fresh tissue at D0 (dotted black circle). (B, C) Cresyl violet staining at D2 and D7 indicated that the hydrogel was correctly injected into the striatum. (D) Detection of Cy5.5 by fluorescence at D7 after the injection of hydrogel loaded with Cy5.5.

striatum (Figure 12C, 12D). It could be reasonably assumed that the darker spherical shape was still the hydrogel at this advanced time point, despite gelation ability was supposed to be lost at D2 due to degradation process in in vitro PBS conditions (Figure 8, $5 \mathrm{wt} \%$ copolymer). Indeed, the degradation kinetics in vivo in brain was expected to be slower than the one studied in vitro. As a confined medium, it is supposed to be less prone to surrounding effects, slowing down erosion process and diffusion of degradation residues. Although further studies are needed to more precisely investigate the impact of the hydrogel in vivo (e.g. neuronal damages and/or inflammation), these results showed that the hydrogel could be successfully injected in a rat brain. 


\section{Conclusion}

We here prepared a PNIPAAm-b-PLA-b-PEG-b-PLA-b-PNIPAAm pentablock, through ROP and NMP combination, for use as an injectable and biodegradable hydrogel in preclinical experiments concerning neurological disorders. In aqueous solution, such amphiphilic block copolymer forms micelles at low temperature which are able to aggregate through intermicellar bridging at body temperature due to its specific architecture. This biomaterial can be efficiently loaded with hydrophobic molecules/drugs into its micelle cores. Micelle mediated drug release is nicely correlated to polymer loss upon degradation over without any burst release. These parameters are clinically relevant as hydrogel injection could avoid repetitive pharmacological substance injections and potentially restrict drug release to areas of interest, therefore limiting additional damages to healthy tissues and reducing side effects ${ }^{53}$. Additionally, the hydrogel mechanical properties properly mimic the ones of soft tissues. The hydrogel and its degradation residues are cytocompatible as highlighted by in vitro neuronal cell development. Finally, as a proof-of-concept, the copolymer solution was successfully injected into the striatum on the rat model. This cerebral structure has been selected as it is frequently altered in several neurodegenerative pathologies. The effects of hydrogel implantation into the brain can be now deepened to identify neuroplasticity mechanisms after brain disorders in preclinical experiment such as traumatic brain injury, stroke or Parkinson disease. Our findings are in accordance to numerous studies, which indicated that hydrogel injection is an encouraging way of treatment in the forthcomings years even if it is currently restricted to animal experiments.

\section{Supporting Information}

SEC, ${ }^{1} \mathrm{H}$ NMR and rheological analysis, CMC determination by DLS, SEM/TEM observations and gelation vs. temperature studies are provided.

\section{Acknowledgments}

This work was supported by public Aix-Marseille Université (AMU) and STAR Carnot Institute grants. We are grateful to T. N. T. Phan and M. Rollet for mechanical and SEC analyses, and A. Campos and M. Cabié from CP2M (AMU) for SEM and TEM analyses. 


\section{References}

(1) Yang, J.-A.; Yeom, J.; Hwang, B. W.; Hoffman, A. S.; Hahn, S. K. In Situ-Forming Injectable Hydrogels for Regenerative Medicine. Prog. Polym. Sci. 2014, 39 (12), 1973-1986.

(2) Pakulska, M. M.; Ballios, B. G.; Shoichet, M. S. Injectable Hydrogels for Central Nervous System Therapy. Biomed. Mater. 2012, 7 (2), 024101.

(3) Nih, L. R.; Carmichael, S. T.; Segura, T. Hydrogels for Brain Repair after Stroke: An Emerging Treatment Option. Curr. Opin. Biotechnol. 2016, 40, 155-163.

(4) Piantino, J.; Burdick, J.; Goldberg, D.; Langer, R.; Benowitz, L. An Injectable, Biodegradable Hydrogel for Trophic Factor Delivery Enhances Axonal Rewiring and Improves Performance after Spinal Cord Injury. Exp. Neurol. 2006, 201 (2), 359-367.

(5) Pritchard, C. D.; O’Shea, T. M.; Siegwart, D. J.; Calo, E.; Anderson, D. G.; Reynolds, F. M.; Thomas, J. A.; Slotkin, J. R.; Woodard, E. J.; Langer, R. An Injectable Thiol-Acrylate Poly(ethylene Glycol) Hydrogel for Sustained Release of Methylprednisolone Sodium Succinate. Biomaterials 2011, 32 (2), 587-597.

(6) Koshy, S. T.; Desai, R. M.; Joly, P.; Li, J.; Bagrodia, R. K.; Lewin, S. A.; Joshi, N. S.; Mooney, D. J. Click-Crosslinked Injectable Gelatin Hydrogels. Adv. Healthc. Mater. 2016, 5 (5), 541-547.

(7) Dong, R.; Zhao, X.; Guo, B.; Ma, P. X. Self-Healing Conductive Injectable Hydrogels with Antibacterial Activity as Cell Delivery Carrier for Cardiac Cell Therapy. ACS Appl. Mater. Interfaces 2016, 8 (27), 17138-17150.

(8) Qu, J.; Zhao, X.; Ma, P. X.; Guo, B. pH-Responsive Self-Healing Injectable Hydrogel Based on N -Carboxyethyl Chitosan for Hepatocellular Carcinoma Therapy. Acta Biomater. 2017, 58, 168-180.

(9) Qu, J.; Zhao, X.; Liang, Y.; Zhang, T.; Ma, P. X.; Guo, B. Antibacterial Adhesive Injectable Hydrogels with Rapid Self-Healing, Extensibility and Compressibility as Wound Dressing for Joints Skin Wound Healing. Biomaterials 2018, 183, 185-199.

(10) Ruel-Gariépy, E.; Leroux, J.-C. In Situ-Forming Hydrogels-review of Temperature-Sensitive Systems. Eur. J. Pharm. Biopharm. 2004, 58 (2), 409-426.

(11) Matanović, M. R.; Kristl, J.; Grabnar, P. A. Thermoresponsive Polymers: Insights into Decisive Hydrogel Characteristics, Mechanisms of Gelation, and Promising Biomedical Applications. Int. J. Pharm. 2014, 472 (1-2), 262-275.

(12) Zhao, J.; Zhao, X.; Guo, B.; Ma, P. X. Multifunctional Interpenetrating Polymer Network Hydrogels Based on Methacrylated Alginate for the Delivery of Small Molecule Drugs and Sustained Release of Protein. Biomacromolecules 2014, 15 (9), 3246-3252.

(13) Zhao, J.; Guo, B.; Ma, P. X. Injectable Alginate Microsphere/PLGA-PEG-PLGA Composite Hydrogels for Sustained Drug Release. RSC Adv. 2014, 4 (34), 17736.

(14) Hotta, R.; Cheng, L. S.; Graham, H. K.; Nagy, N.; Belkind-Gerson, J.; Mattheolabakis, G.; Amiji, M. M.; Goldstein, A. M. Delivery of Enteric Neural Progenitors with 5-HT4 Agonist-Loaded Nanoparticles and Thermosensitive Hydrogel Enhances Cell Proliferation and Differentiation Following Transplantation in Vivo. Biomaterials 2016, 88, 1-11.

(15) Park, M. H.; Joo, M. K.; Choi, B. G.; Jeong, B. Biodegradable Thermogels. Acc. Chem. Res. 2012, $45(3), 424-433$.

(16) Huynh, C. T.; Nguyen, M. K.; Lee, D. S. Injectable Block Copolymer Hydrogels: Achievements and Future Challenges for Biomedical Applications. Macromolecules 2011, 44 (17), 6629-6636.

(17) Li, Z.; Guan, J. Thermosensitive Hydrogels for Drug Delivery. Expert Opin. Drug Deliv. 2011, 8 (8), 991-1007.

(18) Roy, D.; Brooks, W. L. A.; Sumerlin, B. S. New Directions in Thermoresponsive Polymers. Chem. Soc. Rev. 2013, 42 (17), 7214. 
(19) Hacker, M. C.; Klouda, L.; Ma, B. B.; Kretlow, J. D.; Mikos, A. G. Synthesis and Characterization of Injectable, Thermally and Chemically Gelable, Amphiphilic Poly( $N$-Isopropylacrylamide)Based Macromers. Biomacromolecules 2008, 9 (6), 1558-1570.

(20) Malonne, H.; Eeckman, F.; Fontaine, D.; Otto, A.; Vos, L.; Moes, A.; Fontaine, J.; Amighi, K. Preparation of poly(N-Isopropylacrylamide) Copolymers and Preliminary Assessment of Their Acute and Subacute Toxicity in Mice. Eur. J. Pharm. Biopharm. 2005, 61 (3), 188-194.

(21) Alexander, A.; Ajazuddin; Khan, J.; Saraf, S.; Saraf, S. Polyethylene Glycol (PEG)-Poly(NIsopropylacrylamide) (PNIPAAm) Based Thermosensitive Injectable Hydrogels for Biomedical Applications. Eur. J. Pharm. Biopharm. 2014, 88 (3), 575-585.

(22) Ho, E.; Lowman, A.; Marcolongo, M. Synthesis and Characterization of an Injectable Hydrogel with Tunable Mechanical Properties for Soft Tissue Repair. Biomacromolecules 2006, 7 (11), 3223-3228.

(23) Lin, H.-H.; Cheng, Y.-L. In-Situ Thermoreversible Gelation of Block and Star Copolymers of Poly(ethylene Glycol) and Poly( $N$-Isopropylacrylamide) of Varying Architectures.

Macromolecules 2001, 34 (11), 3710-3715.

(24) Kwon, I. K.; Matsuda, T. Photo-Iniferter-Based Thermoresponsive Block Copolymers Composed of Poly(ethylene Glycol) and poly(N-Isopropylacrylamide) and Chondrocyte Immobilization. Biomaterials 2006, 27, 986-995.

(25) Abandansari, H. S.; Aghaghafari, E.; Nabid, M. R.; Niknejad, H. Preparation of Injectable and Thermoresponsive Hydrogel Based on Penta-Block Copolymer with Improved Sol Stability and Mechanical Properties. Polymer 2013, 54 (4), 1329-1340.

(26) Ma, Z.; Nelson, D. M.; Hong, Y.; Wagner, W. R. Thermally Responsive Injectable Hydrogel Incorporating Methacrylate-Polylactide for Hydrolytic Lability. Biomacromolecules 2010, 11 (7), 1873-1881.

(27) Lang, M. Injectable Hydrogel as Stem Cell Scaffolds from the Thermosensitive Terpolymer of NIPAAm/AAc/HEMAPCL. Int. J. Nanomedicine 2012, 4893.

(28) Li, Z.; Wang, F.; Roy, S.; Sen, C. K.; Guan, J. Injectable, Highly Flexible, and Thermosensitive Hydrogels Capable of Delivering Superoxide Dismutase. Biomacromolecules 2009, 10 (12), 33063316.

(29) Cui, Z.; Lee, B. H.; Pauken, C.; Vernon, B. L. Degradation, Cytotoxicity, and Biocompatibility of NIPAAm-Based Thermosensitive, Injectable, and Bioresorbable Polymer Hydrogels. J. Biomed. Mater. Res. A 2011, $98 A$ (2), 159-166.

(30) Guan, J.; Hong, Y.; Ma, Z.; Wagner, W. R. Protein-Reactive, Thermoresponsive Copolymers with High Flexibility and Biodegradability. Biomacromolecules 2008, 9 (4), 1283-1292.

(31) Yang, J.; van Lith, R.; Baler, K.; Hoshi, R. A.; Ameer, G. A. A Thermoresponsive Biodegradable Polymer with Intrinsic Antioxidant Properties. Biomacromolecules 2014, 15 (11), 3942-3952.

(32) McKenzie, M.; Betts, D.; Suh, A.; Bui, K.; Kim, L.; Cho, H. Hydrogel-Based Drug Delivery Systems for Poorly Water-Soluble Drugs. Molecules 2015, 20 (11), 20397-20408.

(33) Hoare, T. R.; Kohane, D. S. Hydrogels in Drug Delivery: Progress and Challenges. Polymer 2008, 49 (8), 1993-2007.

(34) Jeong, B.; Bae, Y. H.; Kim, S. W. Thermoreversible Gelation of PEG-PLGA-PEG Triblock Copolymer Aqueous Solutions. Macromolecules 1999, 32 (21), 7064-7069.

(35) Pettikiriarachchi, J. T. S.; Parish, C. L.; Shoichet, M. S.; Forsythe, J. S.; Nisbet, D. R. Biomaterials for Brain Tissue Engineering. Aust. J. Chem. 2010, 63 (8), 1143.

(36) Chenal, M.; Mura, S.; Marchal, C.; Gigmes, D.; Charleux, B.; Fattal, E.; Couvreur, P.; Nicolas, J. Facile Synthesis of Innocuous Comb-Shaped Polymethacrylates with PEG Side Chains by Nitroxide-Mediated Radical Polymerization in Hydroalcoholic Solutions. Macromolecules 2010, 43 (22), 9291-9303.

(37) Kumar, S.; Achazi, K.; Licha, K.; Manchanda, P.; Haag, R.; Sharma, S. K. Chemo-Enzymatic Synthesis of Dendronized Polymers for Cyanine Dye Encapsulation. Adv. Polym. Technol. 2017. 
(38) Wang, Y.; Alb, A. M.; He, J.; Grayson, S. M. Neutral Linear Amphiphilic Homopolymers Prepared by Atom Transfer Radical Polymerization. Polym Chem 2014, 5 (2), 622-629.

(39) Cheng, W.; Rajendran, R.; Ren, W.; Gu, L.; Zhang, Y.; Chuang, K.-H.; Liu, Y. A Facile Synthetic Approach to a Biodegradable Polydisulfide MRI Contrast Agent. J Mater Chem B 2014, 2 (32), 5295-5301.

(40) Patenaude, M.; Hoare, T. Injectable, Degradable Thermoresponsive Poly( $N$-Isopropylacrylamide) Hydrogels. ACS Macro Lett. 2012, 1 (3), 409-413.

(41) Jiang, X.; Lok, M. C.; Hennink, W. E. Degradable-Brushed pHEMA-pDMAEMA Synthesized via ATRP and Click Chemistry for Gene Delivery. Bioconjug. Chem. 2007, 18 (6), 2077-2084.

(42) Lü, S.; Li, B.; Ni, B.; Sun, Z.; Liu, M.; Wang, Q. Thermoresponsive Injectable Hydrogel for ThreeDimensional Cell Culture: Chondroitin Sulfate Bioconjugated with poly(N-Isopropylacrylamide) Synthesized by RAFT Polymerization. Soft Matter 2011, 7 (22), 10763.

(43) González-Nieto, D.; Fernández-García, L.; Pérez-Rigueiro, J.; Guinea, G.; Panetsos, F. HydrogelsAssisted Cell Engraftment for Repairing the Stroke-Damaged Brain: Chimera or Reality. Polymers 2018, 10 (2), 184.

(44) Lam, J.; Lowry, W. E.; Carmichael, S. T.; Segura, T. Delivery of iPS-NPCs to the Stroke Cavity within a Hyaluronic Acid Matrix Promotes the Differentiation of Transplanted Cells. Adv. Funct. Mater. 2014, 24 (44), 7053-7062.

(45) Baumann, M. D.; Kang, C. E.; Stanwick, J. C.; Wang, Y.; Kim, H.; Lapitsky, Y.; Shoichet, M. S. An Injectable Drug Delivery Platform for Sustained Combination Therapy. J. Controlled Release 2009, 138 (3), 205-213.

(46) Kaech, S.; Banker, G. Culturing Hippocampal Neurons. Nat. Protoc. 2006, 1 (5), 2406-2415.

(47) Tyler, B.; Gullotti, D.; Mangraviti, A.; Utsuki, T.; Brem, H. Polylactic Acid (PLA) Controlled Delivery Carriers for Biomedical Applications. Adv. Drug Deliv. Rev. 2016, 107, 163-175.

(48) Cooperstein, M. A.; Canavan, H. E. Assessment of Cytotoxicity of ( $N$-Isopropyl Acrylamide) and Poly( $N$-Isopropyl Acrylamide)-Coated Surfaces. Biointerphases 2013, 8 (1), 19.

(49) Guatimosim, S.; Guatimosim, C.; Song, L.-S. Imaging Calcium Sparks in Cardiac Myocytes. In Light Microscopy; Chiarini-Garcia, H., Melo, R. C. N., Eds.; Humana Press: Totowa, NJ, 2011; Vol. 689, pp 205-214.

(50) Zhang, H.; Li, W.; Xue, Y.; Zou, F. TRPC1 Is Involved in Ca2+ Influx and Cytotoxicity Following $\mathrm{Pb} 2+$ Exposure in Human Embryonic Kidney Cells. Toxicol. Lett. 2014, 229 (1), 52-58.

(51) O'Callaghan, C.; Bertoux, M.; Hornberger, M. Beyond and below the Cortex: The Contribution of Striatal Dysfunction to Cognition and Behaviour in Neurodegeneration. J. Neurol. Neurosurg. Psychiatry 2014, 85 (4), 371-378.

(52) Paxinos, G.; Watson, C. The Rat Brain in Stereotaxic Coordinates; Amsterdam: Academic Press, 2006.

(53) Wang, J.; Yang, W.; Xie, H.; Song, Y.; Li, Y.; Wang, L. Ischemic Stroke and Repair: Current Trends in Research and Tissue Engineering Treatments. Regen. Med. Res. 2014, 2 (1), 3. 


\section{Graphical abstract}

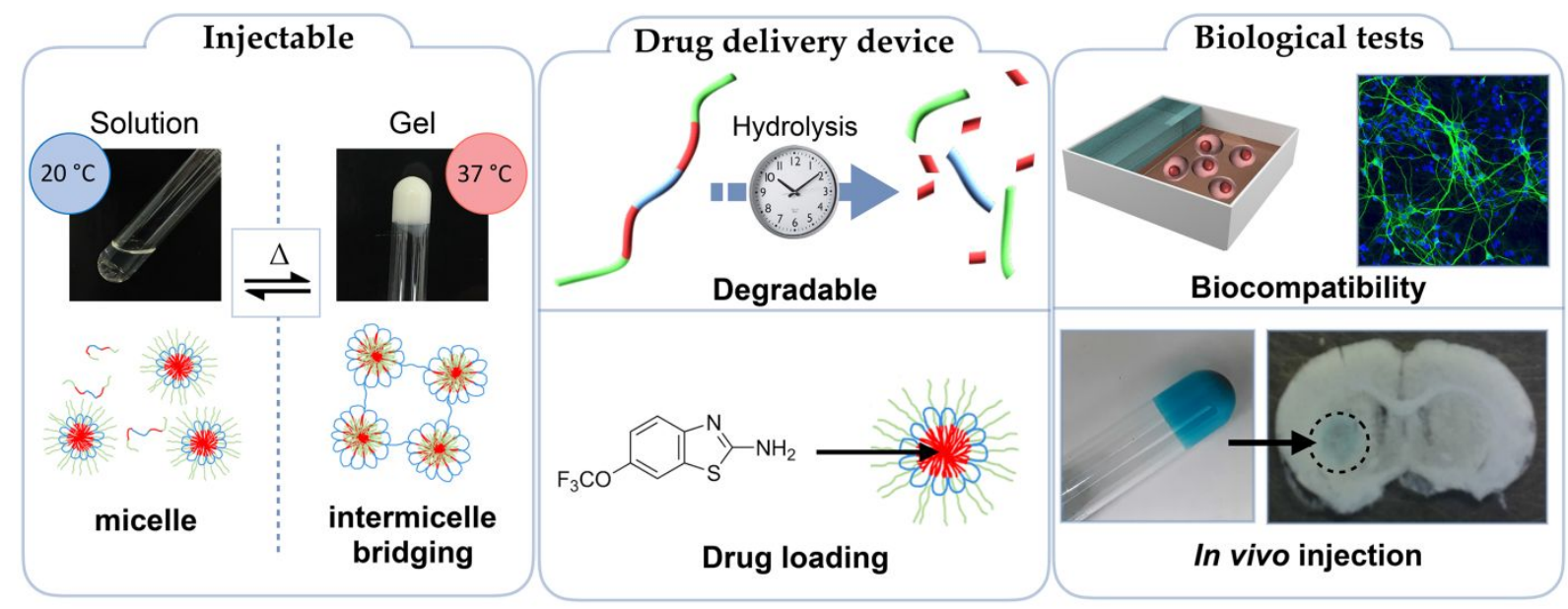

